\title{
An Endeavor to Find Starter Feed Alternatives and Techniques for Zebrafish First-Feeding Larvae: The Effects on Viability, Morphometric Traits, Digestive Enzymes, and Expression of Growth-Related Genes
}

\author{
Seyed-Mohammadreza Samaee, ${ }^{1}$ Behrooz Atashbar Kangarloei, ${ }^{2}$ Farzaneh Noori, ${ }^{3}$ and Alicia Estévez ${ }^{4}$
}

\begin{abstract}
Low and variable growth and survival rates (SR) of 6-10 days postfertilization zebrafish larvae are a problem. This problem seems to be linked to starter feed characteristics. This study is an attempt to find alternatives to address these requests. For this, larvae were fed fresh and lyophilized microalgae (Chlorella, Scenedesmus, and Haematococcus), egg yolk (YOLK), lyophilized Artemia nauplii (LAN), and a combination of them. The lowest SR was observed in algae-fed larvae. All died on day 11 showing an emaciated appearance, similar to starved larvae. The highest SR was observed in YOLK- and LAN-fed larvae, which also showed an elongated anterior part of the body. Negative correlations of SR with vegfaa (vascular endothelial growth factor) and morphometric traits with igf $2 a$ (insulin-like growth factor) were also found and supported by changes at the molecular level. The presence of algae in the digestive tract of the larvae and the observation of fecal droppings indicate that the algae have an appropriate size and are palatable. The increase in the digestive enzyme activity shows the larval effort to digest the algae. The fact that the algae-fed larvae died even before the larvae were kept in starvation indicates the dramatic amount of energy that the larvae spent in microalgae digestion. Although both YOLK- and LAN-fed larvae had the highest SR, LAN group started to feed on Artemia nauplii sooner. This can be linked to the delayed growth in YOLK-fed larvae and an accelerated growth in the case of LAN-fed group. LAN is an expensive feed with negative effects on water quality, whereas YOLK is a cheap and nutritionally balanced feed with fine granular texture that contributes to a larval SR similar to LAN without affecting water quality. In conclusion, microalgae cannot be considered a suitable starter food for zebrafish, whereas LAN and YOLK can be considered good starter feeds.
\end{abstract}

Keywords: Artemia, microalgae, vegfaa and igf $2 a$ gene expression, yolk, zebrafish larvae

\section{Introduction}

$\mathbf{Z}$ EBRAFISH IS A well-known fish model used in a growing number of scientific disciplines ${ }^{1,2}$ due to its rapid organogenesis and transparent body. ${ }^{3}$ The ability to rear zebrafish from egg to adult in the laboratory is of paramount importance, ${ }^{4}$ although raising zebrafish from larvae to juveniles can be laborious, requiring frequent water exchanges and a continuous culture of different live prey. ${ }^{5}$

The most challenging larval stage in this species, as in many other cultured fish, ${ }^{6}$ is the first-feeding phase. The main technical difficulty during this stage is to meet the nutritional demands of the larvae because feed items must be (1) of appropriate size, (2) easy to digest, (3) attractive, (4) available on a continuous basis to support metabolic demands, ${ }^{7}$ and (5) without producing excessive waste in the tanks, ${ }^{1}$ in a way that the larvae receive a good and nutritive feed covering their nutritional demands, while maintaining water quality. ${ }^{4}$ The low ${ }^{4}$ and variable ${ }^{7,8}$ larval growth and survival of zebrafish during the first 5 days of exogenous feeding (days 6-10 postfertilization [dpf]) are an obstacle. The problem affects not only the number of larvae needed but also the time it takes

\footnotetext{
${ }^{1}$ Aquatic Lab, Faculty of Veterinary Medicine, Urmia University, Urmia, Iran.

Departments of ${ }^{2}$ Ecology and Resource Assessment and ${ }^{3}$ Biology and Aquaculture, Artemia and Aquaculture Research Institute, Urmia University, Urmia, Iran.

${ }^{4}$ IRTA-San Carlos de la Rápita, Tarragona, Spain.
} 
to complete experiments, the overall cost of the research, and the quality of adult zebrafish used for breeding and other experiments. ${ }^{4}$

The starter food for first-feeding zebrafish larvae can be either live prey (e.g., paramecia, ${ }^{9}$ saltwater ${ }^{1,4,5,10,11}$ and freshwater rotifers, ${ }^{12}$ and dried rotifer sheet ${ }^{3}$ ) or commercially available powdered feed. ${ }^{7,8}$

Paramecium $(180 \mu \mathrm{m}$ length, $80 \mu \mathrm{m}$ width, and $50 \mu \mathrm{m}$ diameter $^{9}$ ) is the most common live food used for young zebrafish, ${ }^{13-16}$ although its culture is quite complicated, requires repeated subculture, filtration, and sterilization steps, ${ }^{4}$ and does not support the rapid growth of zebrafish juveniles. $^{7,17}$

Saltwater rotifers (Brachionus plicatilis) ${ }^{4}$ have small size, have slow swimming behavior, can be bioencapsulated, ${ }^{6}$ improve larval survival up to $90 \%,{ }^{10}$ and are easier to culture than paramecia. ${ }^{5}$ However, Nakayama et $a .^{3}$ observed that the use of rotifers lead to salt contamination of the culture medium and they cannot survive enough time in freshwater for frequent feeding of zebrafish larvae. Other authors indicated that they can tolerate salinities of 1-97 $\mathrm{ppt}^{18}$ and can survive in nursery tanks for extended periods. ${ }^{4}$ Freshwater rotifers (Brachionus calyciflorus) have also been considered an alternative. ${ }^{12}$ Regardless of the rotifer type, their maintenance and use for newly hatched zebrafish larvae are a challenge for small academic laboratories. To solve the problem, Nakayama et al. ${ }^{3}$ produced a dried rotifer sheet using cryptobiotic (Bdelloid) rotifers ${ }^{19}$ as a simple and convenient live feed for rearing first-feeding zebrafish larvae.

Thus, rearing the live foods is one of the main problems in small-scale low-cost laboratories that do not have access to the necessary funding, equipment, or personnel to maintain large-scale systems usually employed in zebrafish husbandry. ${ }^{5}$ To reduce this problem, some powdered artificial feeds have been developed, ${ }^{20,21}$ although growth and survival rate (SR) of fish fed with them are lower and more variable. ${ }^{7}$ This has been attributed to insufficient/unsuitable nutritional profile, poor attractiveness and digestibility of the feeds. ${ }^{6}$ The processed feeds also contaminate the culture medium ${ }^{22}$ due to leaching of uneaten and decomposing feed particles. ${ }^{6,23}$

Since 1980, enormous efforts have been made to develop microdiets to replace live feed for marine fish larvae. ${ }^{24}$ These microdiets have been also used in zebrafish facilities, ${ }^{25,26}$ but they cannot completely replace live feeds for most marine species, ${ }^{24}$ an important matter that should also be considered in the case of zebrafish.

Zebrafish are omnivorous, eating zooplankton, phytoplankton, insects, worms, and small crustaceans ${ }^{27}$; thus, several organisms can be potentially used as live food for rearing zebrafish first-feeding larvae in low-cost laboratories.

In the case of marine fish larvae (at very early developmental stages), one of the most used techniques is what it is called "green water technique," which consists in the use of microalgae (ALG) directly in the rearing tanks. Microalgae work as stimulants of the nonspecific immune system in the larvae, control the microbial growth in the water, and maintain water quality changing the nitrogenous wastes and $\mathrm{CO}_{2}$ to $\mathrm{O}_{2}{ }^{28,29}$ and reducing $\mathrm{N}$ and $\mathrm{P}$ loads. ${ }^{30}$ Although their role in larval nutrition is not clear, ${ }^{31,32}$ they contribute in the settlement of a healthy intestinal microflora in fish larvae by preventing the development of opportunistic bacteria, 32,33 and reduce the light in the tanks, increasing the contrast to reveal live preys. ${ }^{30,34}$ In mariculture, ALG are also used to produce mass quantities of zooplankton (rotifers and Artemia), which serve as food for larval and early juvenile stages of fish. ${ }^{30,34}$ In Urmia University, freshwater ALG are used to produce a freshwater zooplankton fairy shrimp Branchinecta orientalis, ${ }^{35-37}$ as a potential live food for zebrafish.

ALG are generally used for live food culture; however, their effect as starter food for first-feeding fish larvae has not been evaluated yet. Thus, in this study, in addition to ALG, the suitability of three practical diets as an alternative to processed foods during the first 5 days of exogenous feeding is also evaluated. The potential of three freshwater algae (Chlorella vulgaris [CV], Scenedesmus obliquus [SO], and Haematococcus pluvialis $[H P]$ ), as live foods, together with lyophilized "Artemia nauplii" (LAN) and "egg yolk" (YOLK), as practical diets, to be used as a starter food of choice for rearing first-feeding zebrafish larvae in a low-cost laboratory are the main objectives.

For this, not only were larvae fed with alive microalgaeAALG- (i.e., alive $C$. vulgaris [ACV], alive S. obliquus [ASO], and alive $H$. pluvialis [AHP]), lyophilized microalgae-LALG- (i.e., lyophilized C. vulgaris [LCV], lyophilized S. obliquus [LSO], and lyophilized $H$. pluvialis [LHP]), LAN, and YOLK but also a combination of AALG and LAN (i.e., ACV+LAN, ASO+LAN, and AHP+LAN) and a combination of LALG and LAN (LCV+LAN, LSO+LAN, and LHP+LAN). To tackle these objectives, these 14 dietary treatments were compared taking into account embryo and larval survival, morphologic and morphometric changes in the larvae, and expression level of the genes igf $2 a$ (insulinlike growth factor) and vegfaa (vascular endothelial growth factor).

It has been cited that igfs signaling pathway regulate growth, development, metabolism, and longevity in a wide variety of animals. $^{38}$ The effects of nutritional status ${ }^{39-42}$ and environmental parameters ${ }^{43}$ on igfs expression have already been cited.

vegf gene family provide signals for de novo formation of blood vessels during embryogenesis and for the formation of new blood vessels from preexisting vessels during organogenesis. ${ }^{44}$ The effects of diets supplemented with natural products on vegfs expression have already been cited. ${ }^{45}$

\section{Materials and Methods}

\section{Animals, housing facility, and breeding}

Broodfish (wild type $[\mathrm{AB}$ line]) were purchased from a local supplier, and transferred to Urmia University where they were housed, maintained in a static system, and reproduced in a low-cost facility described in Samaee et al. ${ }^{46}$

\section{Embryo/larvae culture}

Glass beakers of $250 \mathrm{~mL}$ placed in a plastic container equipped with a heater were used for the incubation of eggs, and for larval culture. The beakers filled with $98 \mathrm{~mL}$ system water $^{46}$ were used to incubate 30 fertilized eggs at a temperature of $28^{\circ} \mathrm{C} \pm 0.5^{\circ} \mathrm{C}$ using a 14 -h light/10-h dark photoperiod. The beakers were provided with gentle and continuous aeration.

To prepare the system water, municipal (tap) water was dechlorinated, heated to $28^{\circ} \mathrm{C}$, filtered through an active 
carbon filter, and then conditioned with $240 \mathrm{mg} \mathrm{L}^{-1}$ rock salt $+60 \mathrm{mg} \mathrm{L}^{-1}$ sea salt. Finally, the physiochemical parameters of the system water were tested and adjusted.

Each food group was arranged in four replicates (120 embryos per food group) and the newly hatched larvae reared in the same container. Zebrafish larvae from day 2 (48 hours postfertilization [hpf]) to day 6 (dpf) use the reserves from the yolk sac for development and only $80 \%$ of the water was renewed once daily. From day 7 to $11 \mathrm{dpf}$, larvae were fed two times per day and the water changed after each feeding (Fig. 1). The physicochemical parameters of culture medium before and after adding food groups are presented in Table 1.

Beakers were checked on a daily basis until $11 \mathrm{dpf}$ : day 1 (0-24 hpf; embryogenesis), 2 (24-48 hpf; embryogenesis), 3 (48-72 hpf; hatching), 4 (72-96 hpf; passive feeding), 5 (96120 hpf; passive feeding), 6 (120-144 hpf; onset of exogenous feeding), 7 (144-168 hpf; complete depletion of yolk), $8,9,10,11$ (7-11 feeding on starter food), and 12 (onset of feeding on Artemia nauplii [AN]). At each checking time, dead embryo/larvae were removed, the system water ${ }^{46}$ exchanged, and viability parameters such as hatching and SR calculated.

\section{Preparation of ALG culture and suspension}

A disinfected $500-1000 \mathrm{~mL}$ Pyrex ${ }^{\circledR}$ bottle with a screw cap equipped with an aeration system and placed in a plastic container of 3-5 L was used for ALG culture. The container was half filled with tap water and equipped with a $150 \mathrm{~W}$ heater $\left(25^{\circ} \mathrm{C}\right)$, a thermometer, and a $6 \mathrm{~W}$ light. Nine hundred milliliters of distilled water ( $\mathrm{pH} 8)$ together with $3 \mathrm{~N}$ Modified Bold's Basal Medium and $100 \mathrm{~mL}$ of ALG stock were added and the culture kept at $25^{\circ} \mathrm{C}$ under continuous aeration and light for 1 week. After 1 week, culture 4-5 million ALG per $\mathrm{mL}$ were obtained and stored at $4^{\circ} \mathrm{C}$ until use.

The bottle containing $1 \mathrm{~L} \mathrm{ALG}$ culture was centrifuged ( $8 \mathrm{~S}$ GMP; Sigma, Germany) at $6000 \mathrm{rpm}$ for $5 \mathrm{~min}$ at room temperature (RT), $90 \%-95 \%$ of supernatant discarded, and the ALG resuspended in the remainder supernatant $(50$ $100 \mathrm{~mL}$ ) by shaking the bottle. The ALG concentrated suspension was decanted into a $50 \mathrm{~mL}$ falcon tube, centrifuged at $5000 \mathrm{rpm}$ (5 min at RT), the supernatant discarded, and the falcon tube containing precipitated ALG placed in a freezer $\left(-20^{\circ} \mathrm{C}\right)$ overnight. The cap of the falcon was removed, the falcon placed in a freeze-dryer (SBPE, Zistfarayand Tajhiz Sahand, Iran) overnight, the LALG ground, and stored at $4^{\circ} \mathrm{C}$ until use. For feeding zebrafish larvae, $0.1 \mathrm{~g}$ of this LALG powder was dissolved in $30 \mathrm{~mL}$ water and mixed well. The food group was performed in four replicates (with a total of 30 larvae per replicate). From days 7 to 11 (first feeding larvae), $2 \mathrm{~mL}$ of the suspension was added to beakers, left for $1 \mathrm{~h}$, two times per day, and the water changed after each feeding. Lyophilized $C V$ particulate size in water was as follows: $7-133 \mu \mathrm{m}$; $S O$ : width $=3-10$ and length $=10-30 \mu \mathrm{m}$; and $H P$ : diameter $=20-80 \mu \mathrm{m}$.

In the case of feeding with AALG, $30 \mathrm{~mL}$ of ALG culture was decanted into a $50 \mathrm{~mL}$ falcon tube, centrifuged at 5000 $6000 \mathrm{rpm}$ ( $5 \mathrm{~min}$ at RT), and the supernatant discarded. Thirty milliliters system water was then added, falcon shaken, centrifuged at 5000-6000 rpm ( $5 \mathrm{~min}$ at RT), and the supernatant discarded, repeating this procedure several times. Finally, a known $\mathrm{mL}$ of water was added to washed ALG to achieve a number of 4,500,000 ALG per $\mathrm{mL}$, the falcon tube shaken several times, and the suspension stored at $4{ }^{\circ} \mathrm{C}$ till use. Four different methods (Fig. 1) were used to feed the larvae with AALG. Each method was performed in four replicates (with a total of 30 embryo/larvae per replicate):

Method 1: embryos (0-2 dpf) and passive feeding larvae (3-6 dpf) were cultured in clear water, $80 \%$ of water changed daily. From days 7 to 11 (first feeding larvae), $2 \mathrm{~mL}$ of the ALG suspension was added to the glass beakers (containing $98 \mathrm{~mL}$ medium [a final ALG density of 90,000 ALG per mL] in which 30 larvae had been cultured) and left for $1 \mathrm{~h}$ for larval feeding. This was done twice daily and the medium changed after each feeding.

Method 2: from days 7 to 11, larvae were cultured in green water (90,000 ALG per mL) and ALG precipitates removed (three times daily), followed by checking ALG density and adjusting to 90,000 ALG per $\mathrm{mL}$.

Method 3: fertilized eggs were cultured in green water, from hatching to the day 11 and ALG precipitates removed (three times daily), followed by checking ALG density and adjusting to 90,000 ALG per mL.

Method 4: fertilized eggs were cultured in green water $(90,000$ ALG per $\mathrm{mL})$; on day 6 , the green water replaced with system water. From days 7 to 11 postfertilization, $2 \mathrm{~mL}$ of the ALG suspension was added to the glass beakers (a final ALG density of 90,000 ALG per mL) and left for $1 \mathrm{~h}$. This was done twice daily, medium changed after each feeding.

\section{Fatty acid composition of $A L G$}

For this, $200 \mathrm{mg}$ sample of microalgae was transferred to a $35 \mathrm{~mL}$ glass tube with a Teflon-lined screw cap, $1 \mathrm{~mL}$ of a freshly prepared methanol-sulfuric acid mixture (2.5\% $\mathrm{H}_{2} \mathrm{SO}_{4}$ in $\mathrm{CH}_{3} \mathrm{OH}$ ) was added, gradually heated, and shaken every $10 \mathrm{~min}$, in a water bath to $80^{\circ} \mathrm{C}$, incubated for $1 \mathrm{~h}$, cooled to RT, $500 \mu \mathrm{L}$ hexane and $1.5 \mathrm{~mL} \mathrm{NaCl}(0.9 \%)$ were added, shaken vigorously, centrifuged (at $4000 \mathrm{rpm}$ for $5 \mathrm{~min}$ ), and supernatant (1 $\mu \mathrm{L})$ subjected to gas-liquid chromatography (GC). The determination of fatty acid (FA) composition was done as described by Samaee et al. ${ }^{46}$

\section{Antioxidant profile of ALG}

Dried ALG was used to determine the antioxidant composition. To obtain dried ALG, the glass container with $1 \mathrm{~L}$ microalgae culture was centrifuged at $6000 \mathrm{rpm}$ for $5 \mathrm{~min}$, $90 \%-95 \%$ of supernatant discarded, and the precipitated ALG resuspended in the remainder supernatant $(50-100 \mathrm{~mL})$ by shacking the container. The concentrated ALG suspension was decanted into a Petri dish, transferred to an incubator that had been adjusted to $\geq 50^{\circ} \mathrm{C}$ overnight, and the dried ALG collected into a preweighed $15 \mathrm{~mL}$ falcon tube, labeled, and stored at $4^{\circ} \mathrm{C}$ until biochemical analyses. For the analysis, $0.1 \mathrm{~g}$ ALG was homogenized in $1 \mathrm{~mL}$ acetonitrile, sonicated for $10 \mathrm{~min}$, centrifuged at $2500 \mathrm{rpm}$ for $3 \mathrm{~min}$ at RT, and the supernatant stored at $-20^{\circ} \mathrm{C}$ until use. Around $0.5 \mu \mathrm{L}$ of this supernatant was used for GC-mass analysis using an Agilent 7890 A gas chromatograph coupled to a 5975A mass spectrometer using a HP-5 MS capillary column (5\% phenyl methylpolysiloxane, $30 \mathrm{~m}$ length, $0.25 \mathrm{~mm}$ i.d., and $0.25 \mu \mathrm{m}$ film thickness). The oven temperature was programmed as follows: $3 \mathrm{~min}$ at $80^{\circ} \mathrm{C}$, subsequently $8^{\circ} \mathrm{C} \mathrm{m^{-1 }}$ to $180^{\circ} \mathrm{C}$, and held for $10 \mathrm{~min}$ at $180^{\circ} \mathrm{C}$. Helium was used as carrier gas 

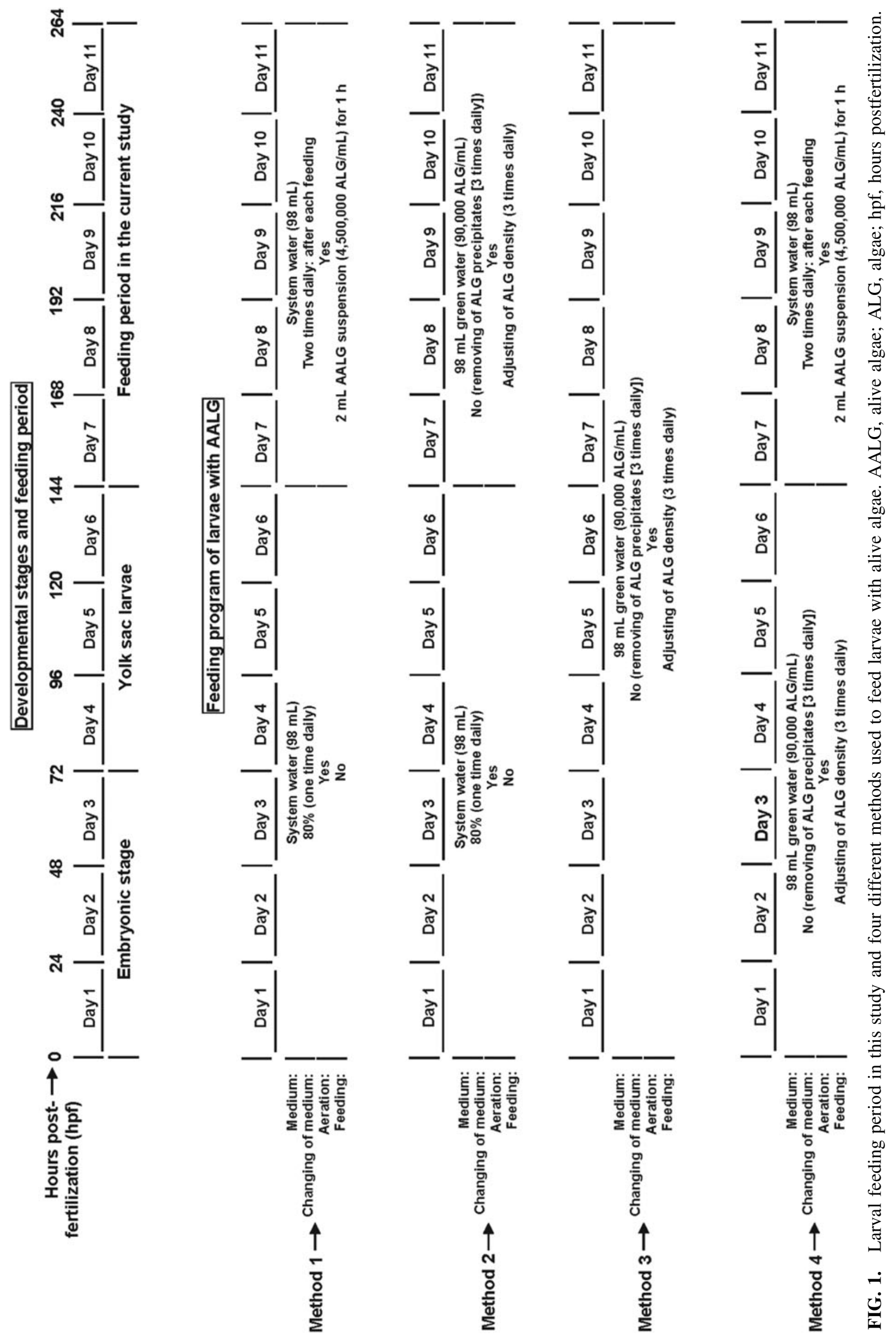


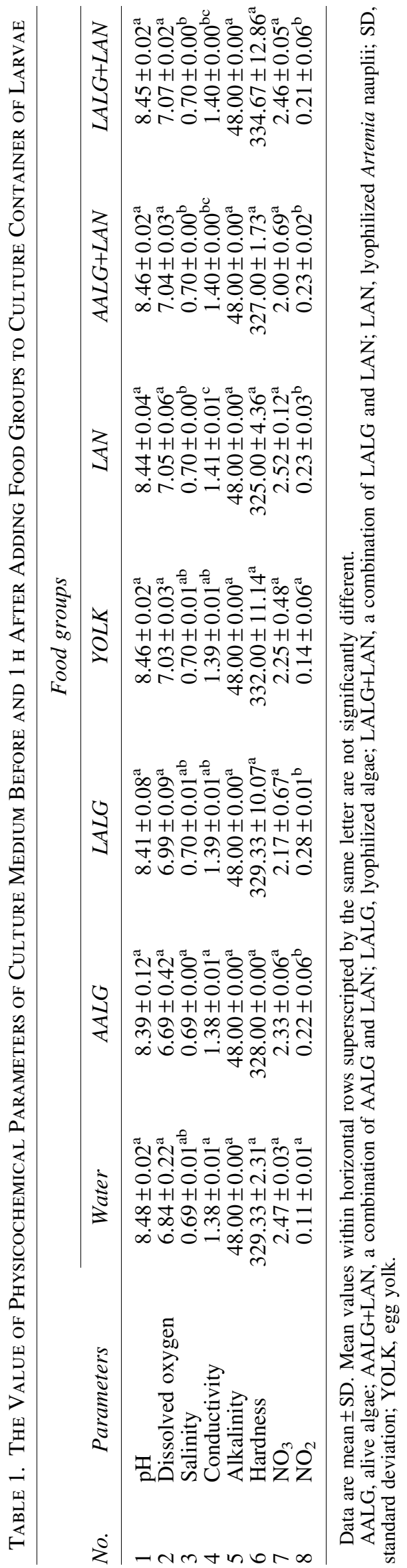

at a flow rate of $1 \mathrm{~mL} \min ^{-1}$ and the electron impact was $70 \mathrm{eV}$. The injector was set in a split mode (split ratio of 1:500) using a mass range acquisition from 40 to $500 \mathrm{~m} / \mathrm{z}$. Antioxidant constituents were identified by using the calculated linear retention indices and mass spectra with those reported in the NIST 05 and Wily 07.

\section{Preparation of AN and LAN suspension}

AN suspension was prepared as in Samaee et al. ${ }^{46}$ The Artemia cysts (AC) (Artemia franciscana, strain VC) used in this study were provided by Can Tho University, Vietnam. AC hatched ( $2 \mathrm{~g} \mathrm{AC}$ per L) after being incubated during $24 \mathrm{~h}$ in filtered tap water with $33 \%$ rock salt, $8.5 \mathrm{pH}$, vigorous and continuous aeration, $28^{\circ} \mathrm{C}$ water temperature, and continuous light. Hatching rate (HR; AN\%) determined newly hatched AN (instar-I; width $=\sim 225$ and length $=\sim 500$ ) harvested and the suspension was prepared washing a known number of AN into a beaker with a different dispersant (system water, $33 \%$ salt water, or collected culture medium) depending on the goal of research. Larvae after $11 \mathrm{dpf}$ were fed two times per day with a concentrated AN suspension $\left(1270 \mathrm{AN} \mathrm{mL}^{-1}\right)$ : $1 \mathrm{~h}$ after turning the light on and $7 \mathrm{~h}$ later.

To prepare LAN suspension, AN were collected in a $100 \mu \mathrm{m}$ mesh basket, washed with distilled water, and transferred to a falcon tube before being freeze-dried as in the case of LALG (see Preparation of ALG Culture and Suspension section). For feeding zebrafish larvae, $0.1 \mathrm{~g}$ of this LAN powder was dissolved in $30 \mathrm{~mL}$ water and mixed well. The food group was performed in four replicates (with a total of 30 larvae per replicate). From days 7 to $11 \mathrm{dpf}$ (first feeding larvae) $2 \mathrm{~mL}$ of the suspension was added to beakers used for larval culture and left for $1 \mathrm{~h}$, two times per day, and the water changed after each feeding.

\section{Larval feeding with a combination of ALG (alive and lyophilized) and $L A N$}

From days 7 to $11 \mathrm{dpf}$ (first feeding larvae), $1 \mathrm{~mL}$ of the AALG (i.e., ACV, ASO, and AHP) or LALG (i.e., LCV, LSO, and LHP) suspension (see Preparation of ALG Culture and Suspension section) and $1 \mathrm{~mL}$ ALN suspension (as combined diet denoted as AALG+LAN [i.e., ACV+LAN, $\mathrm{ASO}+\mathrm{LAN}$, and AHP+LAN] and LALG+LAN [i.e., $\mathrm{LCV}+\mathrm{LAN}$, LSO+LAN, and LHP+LAN]) were added to beakers, left for $1 \mathrm{~h}$, two times per day, and the water changed after each feeding. Each feeding group was performed in four replicates (with a total of 30 larvae per replicate).

\section{Preparation of YOLK suspension and larvae feeding}

A small piece (chickpea size) of a hard-boiled egg was put in a mesh, wrapped, soaked in $50 \mathrm{~mL}$ water, and pressed until a cloudy water was obtained. From days 7 to $11 \mathrm{dpf}$ (first feeding larvae), $2 \mathrm{~mL}$ of the freshly prepared YOLK suspension was added to beakers and left for $1 \mathrm{~h}$. This was done twice daily and water changed after each feeding. The food group was performed in four replicates (with a total of 30 larvae per replicate).

\section{Larval sampling}

Zebrafish larvae were sampled at different ages (dpf) to assess growth, digestive enzyme activity, and gene expression. 
Sampled larvae were transferred to a Petri dish with $20 \mathrm{~mL}$ sterilized phosphate-buffered solution (PBS, one tablet in

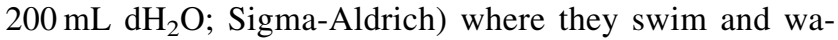
shed. Ten (for gene expression analysis) or 20 (for enzymes activity) larvae taken from each dietary group were pooled in $3 \mathrm{~mL}$ cryotube, labeled, and PBS removed; $1 \mathrm{~mL}$ PBS added for a final washing of the larvae, PBS totally removed, snap-frozen immediately in liquid nitrogen, and stored at $-80^{\circ} \mathrm{C}$ till use.

For morphometric analyses, eight larvae were randomly taken from each dietary group and fixed in $10 \%$ neutral buffered formalin $(10 \mathrm{~mL}$ of $37 \%$ formaldehyde, $0.9 \mathrm{~g}$ sodium chloride, and $100 \mathrm{~mL}$ water ${ }^{47}$ ) for $24 \mathrm{~h}$ and then stored in $4^{\circ} \mathrm{C}$.

\section{Determination of enzyme activity}

To prepare crude enzyme extract, $100 \mu \mathrm{L}$ sodium phosphate buffer $(0.025 \mathrm{M}, \mathrm{pH} 7.2)$ was added to sample (20 frozen larvae, see Gene Expression Analysis section) (1:3), homogenized with a pellet pestle, centrifuged at 10,000 $\mathrm{g}$ for $20 \mathrm{~min}$ at RT (Bekman Coulter centrifuge, Allegra 2IR, Germany), the supernatant collected, divided in four parts, and stored at $-80^{\circ} \mathrm{C}$. The samples were analyzed in triplicate (biological replicates) and each of them examined in triplicate (methodological replicates).

Total soluble protein of larvae was measured by Bradford $^{48}$ method and the results presented as $\mathrm{mg}$ per $\mathrm{mL}$.

Alpha-amylase (E.C.3.2.1.1) activity was determined according to Worthington ${ }^{49}$ using starch as substrate and using Maltose $\left(0-5 \mu \mathrm{mol} \mathrm{mL}^{-1}\right.$ deionized water; Merck, Darmstadt, Germany) to build the standard curve. The $\alpha$-amylase specific activity was defined as $1 \mu \mathrm{mol}$ maltose produced per min per $\mathrm{mg}$ protein at $25^{\circ} \mathrm{C}$.

Bile salt-activated lipase (E.C.3.1.1) was determined using nitrophenyl myristate as substrate according to Iijima et al..$^{50}$ The lipase specific activity was defined as $1 \mu \mathrm{mol}$ of $\mathrm{n}$-nitrophenol released per min per mg protein.

Total alkaline proteases were assayed by the azocasein hydrolysis method described by Garcia-Carreño and Haard. ${ }^{51}$ The unit alkaline protease specific activity was expressed as the change in absorbance at $440 \mathrm{~nm}$ per min per $\mathrm{mg}$ of protein.

\section{Hatching and larval SR}

At the time of water change, dead embryo/larvae were removed and hatching and SR were calculated. The HR was calculated as the ratio of hatched embryos divided by the total number of cultured embryos $\times 100$ at $1-3$ dpf. SR was estimated for zebrafish larvae from $7 \mathrm{dpf}$ (complete depletion of yolk) to $11 \mathrm{dpf}$ (the time when zebrafish larvae start to feed on AN). SR was calculated as the ratio of alive embryo/larvae to total number of cultured embryos $\times 100$.

\section{Larval morphometric characteristics}

Photomicrographs of the fixed larvae were taken at $11 \mathrm{dpf}$ using a stereomicroscope (Zeiss, Germany) equipped with a digital camera (Carl Zeiss, Inc.). Morphometric characteristics (MCs) were measured on digital images using Image $\mathrm{J}$ 1.48 program. Five MCs were recorded and then used to calculate 15 morphometric ratios (Fig. 2).

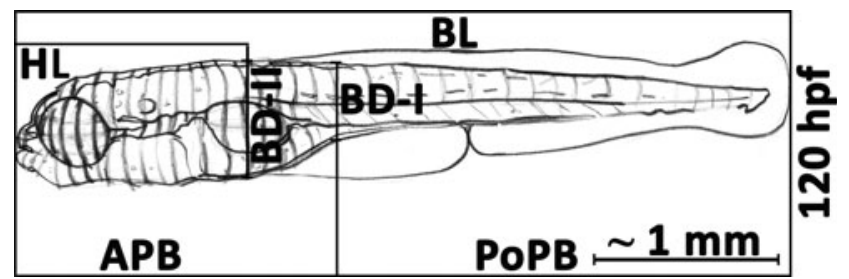

FIG. 2. MCs determined in zebrafish embryos and larvae. The landmarks drawn on the schematic of zebrafish larvae at $120 \mathrm{hpf}$ depict the characteristics that were utilized for screening IM-induced responses. BL: largest horizontal body distance-anterior part of the head to the end of the body. APB: anterior part of the head to the posterior insertion of yolk sac. PoPB: the posterior insertion of yolk sac to the end of the body. HL: anterior part of the head to the place where the head is connected to the body. BD1: vertical distance from posterior insertion of yolk sac to the upper surface of the body. BD2: largest vertical body distance. Fifteen ratios were calculated from the six MCs and included in Tables 6 and $7 \mathrm{BL} / \mathrm{APB}, \mathrm{BL} / \mathrm{PoPB}, \mathrm{BL} / \mathrm{BD} 1, \mathrm{BL} / \mathrm{BD} 2, \mathrm{BL} / \mathrm{HL}$, APB/PoPB, APB/BD1, APB/BD1, APB/HL, PoPB/BD1, PoPB/BD2, PoPB/HL, BD1/BD2, BD1/HL, and BD1/HL. $\mathrm{MCs}$, morphometric characteristics.

\section{Gene expression analysis}

Ten larvae from each group were sampled, washed in PBS (1 tablet in $200 \mathrm{~mL}$ autoclaved $\mathrm{dH}_{2} \mathrm{O}$, P4417; SigmaAldrich), pooled in a $3 \mathrm{~mL}$ cryotube, considered one sample, labeled, snap-frozen in liquid nitrogen, and stored at $-80^{\circ} \mathrm{C}$ until use. Total RNA was extracted using a BioFACT ${ }^{\mathrm{TM}} \mathrm{Kit}$ (RP101-050; Daejeo, Korea) following the manufacturers' instructions, eluted in $20 \mu \mathrm{L}$ RNase-free water, its quality/ quantity determined by spectrometry (NanoDrop-Thermo 2000C; Thermo Fisher Scientific, Wilmington, DE) of total RNA solution, and finally stored at $-80^{\circ} \mathrm{C}$. Total RNA (10 ng) was reverse transcribed into cDNA using a BioFACT Kit (BR441-096) in a $20 \mu \mathrm{L}$ reaction volume by a thermal cycler (model; PEQLAB, Germany), cDNA quantity evaluated by spectrometry, and stored at $-20^{\circ} \mathrm{C}$.

The two target genes (vegfaa and igf $2 a$ ) and a housekeeping gene $\left(\beta\right.$-actin ${ }^{52}$ used as internal standard for the target genes) were considered for gene expression analysis. $\beta$-actin did not change among different food groups. The required primers were designed with Primer Express Software (Applied Biosystems, Foster City, CA) using identical parameters to generate amplicons of similar size. The primers were synthesized by Metabion International AG (Germany) (Table 2).

Quantitative real-time polymerase chain reaction (PCR) was performed using the StepOne Plus ${ }^{\mathrm{TM}}$ system (Applied Biosystems). Each reaction contained $0.5 \mu \mathrm{L}$ diluted cDNA, $0.05 \mu \mathrm{L}$ forward $(10 \mu \mathrm{M})$ and $0.05 \mu \mathrm{L}$ reverse $(10 \mu \mathrm{M})$ primers, and $10 \mu \mathrm{L}$ SYBR Green PCR Master Mix to a final volume of $20 \mu \mathrm{L}$. Amplification followed the PCR cycle condition: $95^{\circ} \mathrm{C}$ for $10 \mathrm{~min}$, followed by 40 cycles of $15 \mathrm{~s}$ at $95^{\circ} \mathrm{C}$ and $1 \mathrm{~min}$ at $61^{\circ} \mathrm{C}$. Each food group was analyzed in triplicate (biological replicates) and each sample in triplicate (methodological replicates). A nontemplate control was performed to ensure that only one PCR product amplified and the stock solutions were not contaminated. Cycle conditions 
Table 2. List of Primer Sets Used in This Study for Real-Time Polymerase Chain Reaction

\begin{tabular}{|c|c|c|c|}
\hline Name & Sequence $\left(5^{\prime}->3^{\prime}\right)$ & NCBI reference sequence & Product size (bp) \\
\hline Beta actin $F$ & 5'-CTTGACTTTGAGCAGGAGATGG-3' & NM_181601.4 & 153 \\
\hline Beta actin R & 5'-AGATTCCATACCCAAGAAGGATGG-3' & & \\
\hline IGF2A F & 5'-GGCAGATGGAGAAAATCCAAGATG-3' & NM_131433.1 & 148 \\
\hline IGF2a R & 5'-TGTTTGTTGCCATTTGGGATGG-3' & & \\
\hline VEGFAa $\mathrm{F}$ & 5'-СТCTCCTCCATCTGTCTGCTG-3' & NM_001110349.2 & 148 \\
\hline VEGFAa R & 5'-GGATACTCCTGGATGATGTCTACC-3' & & \\
\hline GAPDH F & 5'-GATACACGGAGCACCAGGTT-3' & NM_001115114.1 & 156 \\
\hline GAPDH R & 5'- GGTCACATACACGGTTGCTG-3' & & \\
\hline
\end{tabular}

$\mathrm{F}$, forward primer; $\mathrm{R}$, reverse primer.

and amounts of templates were optimized for each primer set in pilot experiments to ensure that amplification was terminated within the linear phase.

A melting curve was also performed to ensure the specificity of PCR amplification. The melt curve protocol was $15 \mathrm{~s}$ at $95^{\circ} \mathrm{C}$ for one time and then $10 \mathrm{~s}$ each at $0.3^{\circ} \mathrm{C}$ increments between $60^{\circ} \mathrm{C}$ for $1 \mathrm{~min}$ and $95^{\circ} \mathrm{C}$ for $10 \mathrm{~min}$. Data collection was enabled at each increment of the melt curve. The amplification efficiency, specificity of primers, and amount of cDNA/sample were evaluated by the standard curve method. Primer pairs were deemed to be acceptable for vegfaa and igf $2 a$ expression analysis if they generated standard curves with an $r^{2}$ value above 0.98 , there was consistency among replicates, and the primer amplification efficiency was 85\%-110\%.

The vegfaa and igf $2 a$ RNA expression levels are presented as cycle threshold values. The relative expression of genes was calculated by the $2^{-\Delta \Delta \mathrm{CT}}$ method $^{53}$ using $\beta$-actin according to the following formula: (1) $\Delta \mathrm{CT}_{\text {Control }}=\mathrm{CT}_{\text {target }}$ gene $\mathrm{CT}_{\text {housekeeping gene, }}$ (2) $\Delta \mathrm{CT}_{\text {Exprimental }}=\mathrm{CT}_{\text {target gene }}-\mathrm{CT}_{\text {house }}$ keeping gene, (3) $\Delta \Delta \mathrm{CT}=\Delta \mathrm{CT}_{\text {Exprimental }}-\Delta \mathrm{CT}_{\mathrm{Control}}$, and (4) fold change: $2^{-\Delta \Delta C T}$.

\section{Statistical analysis}

Data normality was tested by the Anderson-Darling method. Univariate analysis of variance (followed by Duncan's multiple range post hoc test) was used to test the differences among food groups for HR, SR, MCs, enzyme activity, and gene expression level. A $p$-value of 0.05 was accepted for statistical significance. Simple regression models were formulated to characterize endpoints that are correlated to $\mathrm{HR}$ and SR. A $p$-value of $<0.002$ was accepted for determining the level of significance for the regression analysis, considered to be the statistical significance threshold after applying the Bonferroni's adjustment for the critical value of $p<0.05$ to minimize the chance of type I statistical error. All statistical analyses were performed using IBM SPSS (version 20; SPSS, Inc., Chicago, IL) and Excel 2010 (Microsoft Corporation, Redmond, WA).

\section{Results}

Table 3 shows the FA composition of the microalgae used in this study. Significant differences were found among the three freshwater algae (i.e., $C V, S O$, and $H P$ ) in their FA (Table 3) and antioxidant (data not shown) composition.

The embryos cultured in water using the methods 1 and 2 hatched on day 3 (72 hpf, 54\%-66\%) (Table 4, rows 3, 6, and 9), while those cultured in AALG suspensions using the methods 3 and 4 described in Preparation of ALG Culture and Suspension section (Table 4, rows 2, 4, and 8) began to hatch on day 2 (36 hpf, 54\%-92\%), leading to a significant difference between the two groups in HR on day 2 (24-48 hpf) and 3 (48-72 hpf).

The method of culture did not have any effect on SR at different larval stages; therefore method 1 was considered the method of choice in the study to evaluate not only ALGbased starter foods (ALG and ALG+LAN) but also other food groups (YOLK and LAN).

No significant variation was found in SR (Table 5, rows $2-$ 6) and MCs (Table 5, rows 8-28) among the larvae fed AALG (ACV, ASO, and AHP) and LALG (LCV, LSO, and LHP), and between AALG- and LALG-fed larvae; thus the ALG-based groups were considered a single group.

The same results, no significant differences, were found in SR (Table 6, rows 2-6) and MCs (Table 6, rows 8-28) among $\mathrm{A}_{\mathrm{CV}}+\mathrm{LAN}-, \mathrm{A}_{\mathrm{SO}^{-}}+\mathrm{LAN}-$, and $\mathrm{A}_{\mathrm{HP}}+\mathrm{LAN}$-fed, among $\mathrm{L}_{\mathrm{CV}^{+}}{ }^{+}$ LAN-, $\mathrm{L}_{\mathrm{SO}}+\mathrm{LAN}-$, and $\mathrm{L}+\mathrm{LAN}-$ fed, and between AALG+ LAN- and LALG+LAN-fed larvae; therefore the ALG+LANbased groups were considered a single group, as well.

Regarding larval SR, it was observed that on day 7, the starved (STA) larvae had the lowest SR (Fig. 3a), whereas a significant decrease was detected in ALG- and ALG+LANfed larvae at $8 \mathrm{dpf}(28.6 \%$ and $2.4 \%$, respectively; Fig. $3 \mathrm{~b}), 9$ dpf (49.1\% and 6.4\%; Fig. 3c), and $10 \mathrm{dpf}$ (49.4\% and $30.8 \%$; Fig. 3d). On days 8 (Fig. 3b) and 9 (Fig. 3c), the lowest SR was related to ALG-fed larvae followed by STA, while at 10 dpf, the lowest SR was observed in ALG- and ALG+LANfed larvae (Fig. 3d). At $11 \mathrm{dpf}$, all the ALG-fed larvae died and SR was even more reduced in ALG+LAN-fed and STA larvae (Fig. 3e).

The enzyme activity was measured to evaluate the response of larval digestive tract to feeding on ALG at different developmental stages. For this, six groups of larvae were used for enzyme activity determination: (1) LAN-fed larvae that showed the highest SR at $11 \mathrm{dpf}$, the onset of feeding on AN, (2) ALG-fed larvae at $8 \mathrm{dpf}$ (complete absorption of yolk and shift on exogenous feeding), ${ }^{54} 9-10 \mathrm{dpf}$, and $11 \mathrm{dpf},(3)$ larvae before active feeding (BF) at $6 \mathrm{dpf}$ (open digestive tract with enzyme secretion ${ }^{54}$ ), and (4) STA at $11 \mathrm{dpf}$.

The highest and statistically significant $(p<0.05)$ lipase activity ( $\mathrm{U} \mathrm{mg}^{-1}$ protein) was observed in ALG-fed larvae at 9-10 dpf, higher than ALG-fed larvae at $8 \mathrm{dpf}$ (2 times) and $11 \mathrm{dpf}$ (10 times) and the other groups (10 times). ALG- and LAN-fed larvae at $11 \mathrm{dpf}$ had a nonsignificantly $(p>0.05)$ higher (three times) lipase activity than the BF larvae at $6 \mathrm{dpf}$ and STA larvae at $11 \mathrm{dpf}$ (Fig. 4A). 
Table 3. Fatty Acid Composition (\%) of Four Fresh Water Algae Used to Prepare Green Water and ARtemia NaUpliI for Zebrafish Larviculture

\begin{tabular}{|c|c|c|c|c|c|c|c|}
\hline \multirow{2}{*}{ No. } & \multirow[b]{2}{*}{ FAs } & & \multicolumn{5}{|c|}{ Quantitative composition of FAs in four freshwater algae } \\
\hline & & & $\mathrm{CV}(\mathrm{n}=3)$ & $\mathrm{SO}(\mathrm{n}=3)$ & $\mathrm{HP}(\mathrm{n}=3)$ & $\mathrm{SP}(\mathrm{n}=2)$ & $\mathrm{AN}(\mathrm{n}=6)^{47}$ \\
\hline \multicolumn{8}{|l|}{ SFA } \\
\hline 1 & Myristic acid & $14: 0$ & $0.79 \pm 0.05^{\mathrm{a}}$ & $1.65 \pm 0.33^{\mathrm{a}}$ & $1.08 \pm 0.03^{\mathrm{a}}$ & $0.26 \pm 0.02^{\mathrm{a}}$ & $5.53 \pm 3.64^{\mathrm{a}}$ \\
\hline & Palmitic acid & $16: 0$ & $14.77 \pm 0.87^{\mathrm{ab}}$ & $5.87 \pm 0.23^{\mathrm{a}}$ & $21.35 \pm 0.62^{\mathrm{b}}$ & $20.81 \pm 0.32^{\mathrm{b}}$ & 25.09 \\
\hline 3 & Stearic acid & $18: 0$ & $3.53 \pm 0.21^{\mathrm{a}}$ & $12.51 \pm 6.25^{\mathrm{bc}}$ & $14.21 \pm 0.41^{\mathrm{c}}$ & $15.89 \pm 0.14^{\mathrm{c}}$ & $6.03=$ \\
\hline & Arachidic acid & $20: 0$ & $1.85 \pm 0.11^{\mathrm{c}}$ & $0.17 \pm 0.05^{\mathrm{ab}}$ & $0.56 \pm 0.02^{\mathrm{b}}$ & $0.00 \pm 0.00^{\mathrm{a}}$ & $0.20 \pm 0.27^{\mathrm{ab}}$ \\
\hline & Behen & $22: 0$ & $1.74 \pm 0.10^{\mathrm{b}}$ & $1.93 \pm 1.02^{\mathrm{b}}$ & $0.00 \pm 0.00^{\mathrm{a}}$ & $0.00 \pm 0.00^{\mathrm{a}}$ & $0.32 \pm 0.19^{\mathrm{a}}$ \\
\hline & Lignoce & $24: 0$ & $0.00 \pm 0.00^{\mathrm{a}}$ & $0.19 \pm 0.18^{b}$ & $0.00 \pm 0.00^{\mathrm{a}}$ & $1.06 \pm 0.08^{\mathrm{c}}$ & $0.00 \pm 0.00^{\mathrm{a}}$ \\
\hline & $\sum \mathrm{SF}$ & & $22.67 \pm 1.33^{\mathrm{a}}$ & $22.33 \pm 8.06^{\mathrm{a}}$ & $37.20 \pm 1.07^{\mathrm{a}}$ & $38.01 \pm 0.55^{\mathrm{a}}$ & $37.17 \pm 8.78^{\mathrm{a}}$ \\
\hline \multicolumn{8}{|l|}{ MUFA } \\
\hline 8 & ic acid & $14: 1 n-5$ & $0.98 \pm 0.06^{\mathrm{ab}}$ & $0.83 \pm 0.73^{\mathrm{a}}$ & $1.53 \pm 0.04^{\mathrm{b}}$ & $0.69 \pm 0.05^{\mathrm{a}}$ & $0.54 \pm 0.23^{\mathrm{a}}$ \\
\hline 9 & Palm & & & & & & \\
\hline & Vacce & $: 1 n-7$ & $9.22 \pm 0.54^{\mathrm{b}}$ & $1.45 \pm$ & $.02^{\mathrm{a}}$ & $6.67 \pm 0.12^{\mathrm{b}}$ & $10.01 \pm 3.31^{\mathrm{b}}$ \\
\hline & Oleic & & $3.61 \pm 0.21^{\mathrm{a}}$ & $0.00 \pm 0.00^{\mathrm{a}}$ & 0.00 & $7.23 \pm 0.54^{\mathrm{a}}$ & $24.18 \pm 7.99^{\mathrm{b}}$ \\
\hline & Eico & & & & & $0.47 \pm 0.03^{\mathrm{a}}$ & $0.35^{\mathrm{a}}$ \\
\hline & Nerv & $24: 1 n-9$ & $0.00=$ & $8^{\mathrm{b}}$ & 0.0 & $0.03 \pm 0.00^{\mathrm{b}}$ & $0.00 \pm 0.00^{\mathrm{a}}$ \\
\hline & $\sum$ MUFA & & $15.47 \pm 0.91^{\mathrm{b}}$ & $2.82 \pm 0.97^{\mathrm{a}}$ & $2.31 \pm 0.07^{\mathrm{a}}$ & $18.53 \pm 1.01^{\mathrm{b}}$ & $55.80 \pm 3.31^{\mathrm{c}}$ \\
\hline \multirow{2}{*}{\multicolumn{8}{|c|}{ PUFA }} \\
\hline & & & & & & & \\
\hline & Lin & $18: 2 n-6$ & $20.40 \pm 1.20^{\mathrm{b}}$ & $3.91 \pm 3.62^{\mathrm{a}}$ & $21.13 \pm 0.61^{\mathrm{b}}$ & $20.32 \pm 0.16^{\mathrm{b}}$ & $2.83 \pm 1.16^{\mathrm{a}}$ \\
\hline & $\sum n-6$ & & 20. & $2^{\mathrm{a}}$ & 21.1 & & $16^{\mathrm{a}}$ \\
\hline \multicolumn{8}{|c|}{ Omega-3 (n-3) PUFA } \\
\hline 17 & Alpha-linolenic a & $18: 3 n-3$ & $7.94 \pm 0.47^{\mathrm{b}}$ & $7.22 \pm 8.02^{\mathrm{ab}}$ & $11.72 \pm 0.34^{\mathrm{bc}}$ & $16.52 \pm 1.23^{\mathrm{c}}$ & $1.31 \pm 1.37^{\mathrm{a}}$ \\
\hline & $\sum n-3$ PUFA & - & $7.94 \pm 0.47^{b}$ & $7.22 \pm 8.02^{\mathrm{ab}}$ & $11.72 \pm 0.34^{\mathrm{bc}}$ & $16.52 \pm 1.23^{\mathrm{c}}$ & $1.31 \pm 1.37^{\mathrm{a}}$ \\
\hline 19 & $\sum$ PUFA & - & $28.35 \pm 1.66^{\mathrm{c}}$ & $11.13 \pm 4.39^{\mathrm{b}}$ & $32.85 \pm 0.95^{\mathrm{cd}}$ & $36.84 \pm 1.39^{\mathrm{c}}$ & $4.14 \pm 2.49^{\mathrm{a}}$ \\
\hline 20 & $\sum n-6$ PUFA $/ \sum n-3$ PUFA & - & $2.57 \pm 0.00^{\mathrm{a}}$ & $2.14 \pm 2.88^{\mathrm{a}}$ & $1.80 \pm 0.00^{\mathrm{a}}$ & $1.23 \pm 0.08^{\mathrm{a}}$ & $5.57 \pm 4.61^{\mathrm{a}}$ \\
\hline \multirow{2}{*}{\multicolumn{8}{|c|}{ HUFA }} \\
\hline & \multicolumn{7}{|c|}{ Omega-6 $(n-6)$ HUFA } \\
\hline & Eico & & $0.78 \pm 0.05^{\mathrm{d}}$ & & $0.71 \pm 0.02^{\mathrm{c}}$ & $0.16 \pm 0.01^{\mathrm{b}}$ & $00^{\mathrm{a}}$ \\
\hline & Arac & $20: 4$ & & & & $2^{\mathrm{a}}$ & $0.75^{\mathrm{a}}$ \\
\hline 23 & $\sum n-6$ HUFA & - & $0.78 \pm 0.05^{\mathrm{a}}$ & $1.55 \pm 1.38^{\mathrm{a}}$ & $0.71 \pm 0.02^{\mathrm{a}}$ & $0.40 \pm 0.03^{\mathrm{a}}$ & $0.52 \pm 0.75^{\mathrm{a}}$ \\
\hline \multicolumn{8}{|c|}{ Omega-3 (n-3) HUFA } \\
\hline & Eicos & $20: 3 n-3$ & $1.68 \pm 0.10^{\mathrm{c}}$ & $0.00 \pm 0.00^{\mathrm{a}}$ & $0.36 \pm 0.01^{\mathrm{b}}$ & $0.00 \pm 0.00^{\mathrm{a}}$ & $0.00 \pm 0.00^{\mathrm{a}}$ \\
\hline & Eicos & $20: 5 n-3$ & & & & $0.27 \pm 0.02^{\mathrm{a}}$ & $2.37 \pm 3.35^{\mathrm{a}}$ \\
\hline 26 & tenoic acid & $22: 6 n-3$ & $0.47 \pm 0.12^{\mathrm{c}}$ & 0.00 & 1.00 & $0.33 \pm 0.02^{\mathrm{b}}$ & $0.00 \pm 0.00^{\mathrm{a}}$ \\
\hline 27 & $\sum n-3$ HUFA & - & $2.15 \pm 0.02^{\mathrm{a}}$ & $0.47 \pm 0.07^{\mathrm{a}}$ & $2.24 \pm 0.06^{\mathrm{a}}$ & $0.60 \pm 0.04^{\mathrm{a}}$ & $2.37 \pm 3.35^{\mathrm{a}}$ \\
\hline 28 & $\sum$ HUFA & - & $2.94 \pm 0.02^{\mathrm{a}}$ & $2.01 \pm 1.46^{\mathrm{a}}$ & $2.95 \pm 0.09^{\mathrm{a}}$ & $0.99 \pm 0.07^{\mathrm{a}}$ & $2.89 \pm 4.09^{\mathrm{a}}$ \\
\hline 29 & $\sum$ PUFA+HUFA & - & $31.28 \pm 1.68^{\mathrm{b}}$ & $13.14 \pm 2.94^{\mathrm{a}}$ & $35.80 \pm 1.03^{\mathrm{b}}$ & $37.83 \pm 1.46^{\mathrm{b}}$ & $7.03 \pm 6.55^{\mathrm{a}}$ \\
\hline 30 & $\sum n-6 / \sum n-3$ & - & $2.10 \pm 0.03^{\mathrm{a}}$ & $2.25 \pm 2.98^{\mathrm{a}}$ & $1.56 \pm 0.0^{\mathrm{a}}$ & $1.21 \pm 0.08^{\mathrm{a}}$ & $3.15 \pm 3.13^{\mathrm{a}}$ \\
\hline
\end{tabular}

Data are mean \pm SD. Mean values within horizontal rows superscripted by the same letter are not significantly different.

$n$ : Number of specimens for each alga and AN.

AN, Artemia nauplii; CV, Chlorella vulgaris; FA, fatty acid; SO, Scenedesmus obliquus; HP, Haematococcus pluvialis; HUFA, highunsaturated FA; MUFA, monounsaturated FAs; PUFAs, polyunsaturated fatty acids; SFA, saturated fatty acids; $S P$, Spirulina $s p$.

The highest amylase activity was observed in the ALG-fed larvae at 9-10 dpf (4 and 11 times higher than ALG-fed larvae at 8 and $11 \mathrm{dpf}$, respectively). No significant differences were observed among STA, ALG-fed, and LAN-fed larvae at $11 \mathrm{dpf}$, concerning amylase activity, being lowest in BF at 6 dpf (Fig. 4B).

Alkaline protease activity ( $\mathrm{U} \mathrm{mg}^{-1}$ protein) was only detected in LAN-fed larvae at $11 \mathrm{dpf}$ (Fig. 4C).

Significant variations among the groups (YOLK-, LAN-, ALG-, ALG+LAN-fed, and STA larvae) were observed concerning MCs at $11 \mathrm{dpf}$ (Table 7). Thus, differences were found in the length of the anterior part of the body (APB,
Fig. 5A) and the ratios body length/head length (BL/HL, Fig. 5C), body length/anterior part of the body (BL/APB, Fig. 5E), anterior part of the body/posterior part of the body (APB/PoPB, Fig. 5G), and posterior part of the body/head length (PoPB/HL, Fig. 5I). These five MCs were significantly correlated to SR at $11 \mathrm{dpf}$ (Fig. 5B, D, F, H, J) in the form of linear (Fig. 5B, F, H) and quadratic (Fig. 5D, J) functions, while other ratios were not significantly associated to SR.

The expression level of vegfaa was downregulated (by 0.47 -fold) in the STA larvae relative to control group, whereas it increased in the other groups. A significant variation among the groups in terms of vegfaa expression 
Table 4. Hatching Rate (Mean \pm Standard Deviation) of Zebrafish Larvae Cultured Using System Water and Microalgae (Green Water Technique) at Different Days Postfertilization

\begin{tabular}{|c|c|c|c|c|}
\hline \multirow[b]{2}{*}{ Methods } & \multicolumn{4}{|c|}{$H R$} \\
\hline & Day 1 & Day 2 & Day 3 & Day 4 \\
\hline \multicolumn{5}{|l|}{$C V$} \\
\hline Green water (Method-1 and 2) & $0.00 \pm 0.00^{\mathrm{a}}$ & $78.27 \pm 25.43^{b}$ & $100.00 \pm 0.00^{\mathrm{b}}$ & $100.00 \pm 0.00^{\mathrm{a}}$ \\
\hline System water (Method-3 and 4) & $0.00 \pm 0.00^{\mathrm{a}}$ & $0.00 \pm 0.00^{\mathrm{a}}$ & $65.59 \pm 20.04^{\mathrm{a}}$ & $100.00 \pm 0.00^{\mathrm{a}}$ \\
\hline \multicolumn{5}{|l|}{ SO } \\
\hline Green water (Method-1 and 2) & $0.00 \pm 0.00^{\mathrm{a}}$ & $53.98 \pm 32.25^{\mathrm{b}}$ & $100.00 \pm 0.00^{\mathrm{b}}$ & $100.00 \pm 0.00^{\mathrm{a}}$ \\
\hline System water (Method-3 and 4) & $0.00 \pm 0.00^{\mathrm{a}}$ & $0.00 \pm 0.00^{\mathrm{a}}$ & $57.58 \pm 9.74^{\mathrm{a}}$ & $100.00 \pm 0.00^{\mathrm{a}}$ \\
\hline \multicolumn{5}{|l|}{$H P$} \\
\hline Green water (Method-1 and 2) & $0.00 \pm 0.00^{\mathrm{a}}$ & $92.31 \pm 13.32^{b}$ & $100.00 \pm 0.00^{\mathrm{b}}$ & $100.00 \pm 0.00^{\mathrm{a}}$ \\
\hline System water (Method-3 and 4) & $0.00 \pm 0.00^{\mathrm{a}}$ & $0.39 \pm 0.93^{\mathrm{a}}$ & $54.33 \pm 23.44^{\mathrm{a}}$ & $100.00 \pm 0.00^{\mathrm{a}}$ \\
\hline
\end{tabular}

Different superscript letters indicate significant differences. See Preparation of ALG Culture and Suspension section for the methods used in zebrafish larviculture.

$\mathrm{HR}$, hatching rate.

Table 5. Survival Rate (SR\%, Days 7 to 11 DPf) And Morphometric Characteristics (11 DPf) OF Zebrafish Larvae Fed on Six Algal Groups: Three Alive Algae (ACV, ASO, and AHP) and Three Lyophilized Algae (LCV, LSO, AND LHP)

\begin{tabular}{|c|c|c|c|c|c|c|}
\hline \multirow[b]{2}{*}{ Variables } & \multicolumn{6}{|c|}{ Six algal feed groups } \\
\hline & $A C V$ & $A S O$ & $A H P$ & $L C V$ & LSO & $L H P$ \\
\hline \multicolumn{7}{|l|}{ SR } \\
\hline SR-7 & $99.69 \pm 0.88^{\mathrm{a}}$ & $99.52 \pm 1.36^{\mathrm{a}}$ & $100.00 \pm 0.00^{\mathrm{a}}$ & $100.00 \pm 0.00^{\mathrm{a}}$ & $94.52 \pm 5.36^{\mathrm{a}}$ & $100.00 \pm 0.00^{\mathrm{a}}$ \\
\hline SR-8 & $71.70 \pm 7.17^{\mathrm{a}}$ & $71.49 \pm 9.03^{\mathrm{a}}$ & $73.54 \pm 10.84^{\mathrm{a}}$ & $72.54 \pm 11.07^{\mathrm{a}}$ & $60.95 \pm 12.58^{\mathrm{a}}$ & $70.28 \pm 3.57^{\mathrm{a}}$ \\
\hline SR-9 & $49.18 \pm 6.92^{\mathrm{a}}$ & $54.27 \pm 8.12^{\mathrm{a}}$ & $49.70 \pm 11.32^{\mathrm{a}}$ & $46.35 \pm 9.36^{\mathrm{a}}$ & $44.76 \pm 4.86^{\mathrm{a}}$ & $51.23 \pm 3.85^{\mathrm{a}}$ \\
\hline SR-10 & $22.23 \pm 5.95^{\mathrm{a}}$ & $17.68 \pm 8.98^{\mathrm{a}}$ & $21.76 \pm 9.40^{\mathrm{a}}$ & $28.73 \pm 3.99^{\mathrm{a}}$ & $21.90 \pm 3.67^{\mathrm{a}}$ & $22.57 \pm 4.73^{\mathrm{a}}$ \\
\hline SR-11 & $0.00 \pm 0.00^{\mathrm{a}}$ & $0.00 \pm 0.00^{\mathrm{a}}$ & $0.00 \pm 0.00^{\mathrm{a}}$ & $0.00 \pm 0.00^{\mathrm{a}}$ & $0.00 \pm 0.00^{\mathrm{a}}$ & $0.00 \pm 00.0^{\mathrm{a}}$ \\
\hline \multicolumn{7}{|l|}{$\mathrm{MCs}$} \\
\hline BL & $3.57 \pm 0.13^{\mathrm{a}}$ & $3.58 \pm 0.12^{\mathrm{a}}$ & $3.71 \pm 0.06^{\mathrm{b}}$ & $3.64 \pm 0.16^{\mathrm{a}}$ & $3.94 \pm 0.02^{\mathrm{a}}$ & $3.65 \pm 0.11^{\mathrm{a}}$ \\
\hline HL & $0.91 \pm 0.05^{\mathrm{a}}$ & $0.88 \pm 0.02^{\mathrm{a}}$ & $0.93 \pm 0.04^{\mathrm{b}}$ & $0.88 \pm 0.02^{\mathrm{a}}$ & $1.05 \pm 0.00^{\mathrm{a}}$ & $0.87 \pm 0.10^{\mathrm{a}}$ \\
\hline APB & $1.18 \pm 0.03^{\mathrm{a}}$ & $1.16 \pm 0.02^{\mathrm{a}}$ & $1.22 \pm 0.03^{\mathrm{a}}$ & $1.19 \pm 0.03^{\mathrm{a}}$ & $1.34 \pm 0.03^{\mathrm{a}}$ & $1.23 \pm 0.10^{\mathrm{a}}$ \\
\hline PoPB & $2.39 \pm 0.14^{\mathrm{a}}$ & $2.42 \pm 0.12^{\mathrm{a}}$ & $2.48 \pm 0.02^{\mathrm{a}}$ & $2.46 \pm 0.15^{\mathrm{a}}$ & $2.61 \pm 0.02^{\mathrm{a}}$ & $2.39 \pm 0.11^{\mathrm{a}}$ \\
\hline BD1 & $0.34 \pm 0.04^{\mathrm{a}}$ & $0.32 \pm 0.01^{\mathrm{a}}$ & $0.33 \pm 0.02^{\mathrm{a}}$ & $0.32 \pm 0.02^{\mathrm{a}}$ & $0.31 \pm 0.01^{\mathrm{a}}$ & $0.33 \pm 0.03^{\mathrm{a}}$ \\
\hline BD2 & $0.48 \pm 0.03^{\mathrm{ab}}$ & $0.52 \pm 0.03^{\mathrm{a}}$ & $0.51 \pm 0.03^{\mathrm{a}}$ & $0.48 \pm 0.01^{\mathrm{b}}$ & $0.47 \pm 0.02^{\mathrm{ab}}$ & $0.50 \pm 0.00^{\mathrm{ab}}$ \\
\hline $\mathrm{BL} / \mathrm{APB}$ & $3.04 \pm 0.15^{\mathrm{a}}$ & $3.09 \pm 0.14^{\mathrm{a}}$ & $3.04 \pm 0.04^{\mathrm{a}}$ & $3.06 \pm 0.13^{\mathrm{a}}$ & $2.93 \pm 0.05^{\mathrm{a}}$ & $2.97 \pm 0.20^{\mathrm{a}}$ \\
\hline $\mathrm{BL} / \mathrm{PoPB}$ & $1.49 \pm 0.03^{\mathrm{a}}$ & $1.48 \pm 0.02^{\mathrm{a}}$ & $1.49 \pm 0.01^{\mathrm{a}}$ & $1.48 \pm 0.03^{\mathrm{a}}$ & $1.51 \pm 0.02^{\mathrm{a}}$ & $1.53 \pm 0.05^{\mathrm{a}}$ \\
\hline $\mathrm{BL} / \mathrm{BD} 1$ & $10.66 \pm 0.73^{\mathrm{a}}$ & $11.33 \pm 0.17^{\mathrm{ab}}$ & $11.37 \pm 0.74^{b}$ & $11.26 \pm 1.07^{\mathrm{ab}}$ & $12.63 \pm 0.56^{\mathrm{ab}}$ & $10.97 \pm 0.67^{\mathrm{a}}$ \\
\hline $\mathrm{BL} / \mathrm{BD} 2$ & $7.51 \pm 0.14^{\mathrm{a}}$ & $6.95 \pm 0.51^{\mathrm{a}}$ & $7.25 \pm 0.46^{\mathrm{b}}$ & $7.51 \pm 0.24^{\mathrm{a}}$ & $8.46 \pm 0.50^{\mathrm{a}}$ & $7.33 \pm 0.28^{\mathrm{a}}$ \\
\hline $\mathrm{BL} / \mathrm{HL}$ & $3.92 \pm 0.11^{\mathrm{a}}$ & $4.05 \pm 0.17^{\mathrm{a}}$ & $3.97 \pm 0.18^{\mathrm{a}}$ & $4.11 \pm 0.18^{\mathrm{a}}$ & $3.77 \pm 0.03^{\mathrm{a}}$ & $4.20 \pm 0.40^{\mathrm{a}}$ \\
\hline $\mathrm{APB} / \mathrm{PoPB}$ & $0.49 \pm 0.03^{\mathrm{a}}$ & $0.48 \pm 0.03^{\mathrm{a}}$ & $0.49 \pm 0.01^{\mathrm{a}}$ & $0.49 \pm 0.03^{\mathrm{a}}$ & $0.51 \pm 0.02^{\mathrm{a}}$ & $0.52 \pm 0.05^{\mathrm{a}}$ \\
\hline $\mathrm{APB} / \mathrm{BD} 1$ & $3.52 \pm 0.40^{\mathrm{a}}$ & $3.67 \pm 0.11^{\mathrm{a}}$ & $3.75 \pm 0.29^{b}$ & $3.67 \pm 0.21^{\mathrm{a}}$ & $4.31 \pm 0.27^{\mathrm{a}}$ & $3.70 \pm 0.26^{\mathrm{a}}$ \\
\hline $\mathrm{APB} / \mathrm{BD} 2$ & $2.47 \pm 0.16^{\mathrm{a}}$ & $2.25 \pm 0.11^{\mathrm{a}}$ & $2.39 \pm 0.18^{\mathrm{b}}$ & $2.46 \pm 0.06^{\mathrm{a}}$ & $2.89 \pm 0.22^{\mathrm{a}}$ & $2.48 \pm 0.22^{\mathrm{a}}$ \\
\hline $\mathrm{APB} / \mathrm{HL}$ & $1.29 \pm 0.07^{\mathrm{a}}$ & $1.31 \pm 0.02^{\mathrm{a}}$ & $1.31 \pm 0.05^{\mathrm{a}}$ & $1.34 \pm 0.00^{\mathrm{a}}$ & $1.28 \pm 0.03^{\mathrm{ab}}$ & $1.42 \pm 0.04^{\mathrm{b}}$ \\
\hline PoPB/BD1 & $7.13 \pm 0.37^{\mathrm{a}}$ & $7.66 \pm 0.23^{\mathrm{ab}}$ & $7.61 \pm 0.46^{\mathrm{b}}$ & $7.61 \pm 0.88^{\mathrm{ab}}$ & $8.36 \pm 0.26^{\mathrm{ab}}$ & $7.18 \pm 0.52^{\mathrm{a}}$ \\
\hline $\mathrm{PoPB} / \mathrm{BD} 2$ & $5.02 \pm 0.02^{\mathrm{a}}$ & $4.70 \pm 0.42^{\mathrm{a}}$ & $4.86 \pm 0.27^{\mathrm{b}}$ & $5.07 \pm 0.26^{\mathrm{a}}$ & $5.61 \pm 0.26^{\mathrm{a}}$ & $4.80 \pm 0.22^{\mathrm{a}}$ \\
\hline PoPB/HL & $2.62 \pm 0.07^{\mathrm{a}}$ & $2.74 \pm 0.16^{\mathrm{a}}$ & $2.66 \pm 0.12^{\mathrm{a}}$ & $2.78 \pm 0.18^{\mathrm{a}}$ & $2.49 \pm 0.01^{\mathrm{a}}$ & $2.76 \pm 0.34^{\mathrm{a}}$ \\
\hline $\mathrm{BD} 1 / \mathrm{BD} 2$ & $0.71 \pm 0.04^{\mathrm{b}}$ & $0.61 \pm 0.04^{\mathrm{ab}}$ & $0.64 \pm 0.03^{\mathrm{ab}}$ & $0.67 \pm 0.04^{\mathrm{a}}$ & $0.67 \pm 0.01^{\mathrm{ab}}$ & $0.67 \pm 0.07^{\mathrm{ab}}$ \\
\hline $\mathrm{BD} 1 / \mathrm{HL}$ & $0.37 \pm 0.03^{\mathrm{b}}$ & $0.36 \pm 0.01^{\mathrm{b}}$ & $0.35 \pm 0.03^{\mathrm{a}}$ & $0.37 \pm 0.02^{\mathrm{b}}$ & $0.30 \pm 0.01^{\mathrm{b}}$ & $0.38 \pm 0.03^{\mathrm{b}}$ \\
\hline $\mathrm{BD} 2 / \mathrm{HL}$ & $0.52 \pm 0.02^{\mathrm{b}}$ & $0.58 \pm 0.02^{b}$ & $0.55 \pm 0.04^{\mathrm{a}}$ & $0.55 \pm 0.02^{\mathrm{b}}$ & $0.45 \pm 0.02^{\mathrm{b}}$ & $0.57 \pm 0.06^{\mathrm{b}}$ \\
\hline
\end{tabular}

Mean \pm SD, different superscript letters indicate significant differences. Number of specimens ( $n$ ) for SR and MCs are 200 and 6 , respectively. Alive microalgae (ACV, ASO, and AHP), lyophilized microalgae (LCV, LSO, and LHP). See the legend of Figure 2 for abbreviations of MCs.

ACV, alive Chlorella vulgaris; AHP, alive Haematococcus pluvialis; ASO, alive Scenedesmus obliquus; LCV, lyophilized C. vulgaris; LHP, lyophilized H. pluvialis; LSO, lyophilized S. obliquus; MCs, morphometric characteristics; SR, survival rate. 
Table 6. Survival Rate (SR\%, Days 7 to 11 DPF) and Morphometric Characteristics (11 DPF) of Zebrafish Larvae Fed on Six Algal Groups Combined With LAN: Three Alive Algae Combined with LAN (ACV+LAN, ASO+LAN, AND AHP+LAN) AND ThreE Lyophilized Algae Combined WITH LAN (LCV+LAN, LSO+LAN, AND LHP+LAN)

\begin{tabular}{|c|c|c|c|c|c|c|c|}
\hline \multirow{2}{*}{\multicolumn{2}{|c|}{ Variables }} & \multicolumn{6}{|c|}{ Six algal group in combination with LAN } \\
\hline & & $A C V+L A N$ & $A S O+L A N$ & $A H P+L A N$ & $L C V+L A N$ & $L S O+L A N$ & $L H P+L A N$ \\
\hline \multicolumn{8}{|l|}{ SR } \\
\hline & SR-7 & $98.85 \pm 1.99^{\mathrm{a}}$ & $100.00 \pm 0.00^{\mathrm{a}}$ & $100.00 \pm 0.00^{\mathrm{a}}$ & $98.33 \pm 2.36^{\mathrm{a}}$ & $100.00 \pm 0.00^{\mathrm{a}}$ & $100.00 \pm 0.00^{\mathrm{a}}$ \\
\hline & SR-8 & $98.85 \pm 1.99^{\mathrm{a}}$ & $97.66 \pm 2.03^{\mathrm{a}}$ & $95.24 \pm 8.25^{\mathrm{a}}$ & $93.33 \pm 9.43^{\mathrm{a}}$ & $98.65 \pm 1.91^{\mathrm{a}}$ & $98.28 \pm 2.44^{\mathrm{a}}$ \\
\hline & SR-9 & $91.24 \pm 4.73^{\mathrm{a}}$ & $96.38 \pm 0.20^{\mathrm{a}}$ & $92.86 \pm 12.37^{\mathrm{a}}$ & $90.56 \pm 10.21^{\mathrm{a}}$ & $93.24 \pm 9.56^{\mathrm{a}}$ & $93.52 \pm 0.59^{\mathrm{a}}$ \\
\hline & SR-10 & $72.13 \pm 8.97^{\mathrm{a}}$ & $65.25 \pm 7.97^{\mathrm{a}}$ & $70.00 \pm 6.13^{\mathrm{a}}$ & $70.00 \pm 14.14^{\mathrm{a}}$ & $71.28 \pm 5.26^{\mathrm{a}}$ & $62.64 \pm 5.69^{\mathrm{a}}$ \\
\hline & SR-11 & $27.66 \pm 3.56^{\mathrm{a}}$ & $27.79 \pm 2.89^{\mathrm{a}}$ & $26.53 \pm 11.09^{\mathrm{a}}$ & $29.44 \pm 10.21^{\mathrm{a}}$ & $32.77 \pm 10.99^{\mathrm{a}}$ & $27.22 \pm 4.36^{\mathrm{a}}$ \\
\hline \multicolumn{8}{|l|}{$\mathrm{MCs}$} \\
\hline & $\mathrm{BL}$ & $3.73 \pm 0.04^{\mathrm{a}}$ & $3.57 \pm 0.26^{\mathrm{a}}$ & $3.74 \pm 0.15^{\mathrm{a}}$ & $3.69 \pm 0.28^{\mathrm{a}}$ & $3.88 \pm 0.19^{\mathrm{a}}$ & $3.60 \pm 0.27^{\mathrm{a}}$ \\
\hline & $\mathrm{HL}$ & $1.00 \pm 0.08^{\mathrm{a}}$ & $0.90 \pm 0.06^{\mathrm{a}}$ & $0.96 \pm 0.09^{\mathrm{a}}$ & $0.94 \pm 0.14^{\mathrm{a}}$ & $0.96 \pm 0.07^{\mathrm{a}}$ & $0.89 \pm 0.05^{\mathrm{a}}$ \\
\hline & APB & $1.25 \pm 0.08^{\mathrm{a}}$ & $1.16 \pm 0.06^{\mathrm{a}}$ & $1.29 \pm 0.10^{\mathrm{a}}$ & $1.27 \pm 0.18^{\mathrm{a}}$ & $1.32 \pm 0.08^{\mathrm{a}}$ & $1.17 \pm 0.06^{\mathrm{a}}$ \\
\hline & PoPB & $2.50 \pm 0.11^{\mathrm{a}}$ & $2.45 \pm 0.19^{\mathrm{a}}$ & $2.44 \pm 0.10^{\mathrm{a}}$ & $2.45 \pm 0.08^{\mathrm{a}}$ & $2.64 \pm 0.12^{\mathrm{a}}$ & $2.44 \pm 0.21^{\mathrm{a}}$ \\
\hline & BD1 & $0.33 \pm 0.07^{\mathrm{a}}$ & $0.34 \pm 0.05^{\mathrm{a}}$ & $0.35 \pm 0.01^{\mathrm{a}}$ & $0.33 \pm 0.04^{\mathrm{a}}$ & $0.33 \pm 0.02^{\mathrm{a}}$ & $0.32 \pm 0.01^{\mathrm{a}}$ \\
\hline & $\mathrm{BD} 2$ & $0.50 \pm 0.04^{\mathrm{a}}$ & $0.51 \pm 0.03^{\mathrm{a}}$ & $0.55 \pm 0.06^{\mathrm{a}}$ & $0.54 \pm 0.12^{\mathrm{a}}$ & $0.52 \pm 0.04^{\mathrm{a}}$ & $0.53 \pm 0.04^{\mathrm{a}}$ \\
\hline & $\mathrm{BL} / \mathrm{APB}$ & $2.99 \pm 0.22^{\mathrm{a}}$ & $3.09 \pm 0.07^{\mathrm{a}}$ & $2.92 \pm 0.19^{\mathrm{a}}$ & $2.93 \pm 0.20^{\mathrm{a}}$ & $2.94 \pm 0.06^{\mathrm{a}}$ & $3.08 \pm 0.06^{\mathrm{a}}$ \\
\hline & $\mathrm{BL} / \mathrm{PoPB}$ & $1.49 \pm 0.05^{\mathrm{a}}$ & $1.46 \pm 0.00^{\mathrm{a}}$ & $1.53 \pm 0.03^{\mathrm{a}}$ & $1.51 \pm 0.07^{\mathrm{a}}$ & $1.47 \pm 0.12^{\mathrm{a}}$ & $1.47 \pm 0.01^{\mathrm{a}}$ \\
\hline & $\mathrm{BL} / \mathrm{BD} 1$ & $11.50 \pm 2.17^{\mathrm{a}}$ & $10.59 \pm 0.88^{\mathrm{a}}$ & $10.64 \pm 0.16^{\mathrm{a}}$ & $11.23 \pm 0.59^{\mathrm{a}}$ & $11.78 \pm 1.10^{\mathrm{a}}$ & $11.25 \pm 1.31^{\mathrm{a}}$ \\
\hline & $\mathrm{BL} / \mathrm{BD} 2$ & $7.45 \pm 0.55^{\mathrm{a}}$ & $7.01 \pm 0.07^{\mathrm{a}}$ & $6.79 \pm 0.46^{\mathrm{a}}$ & $6.98 \pm 1.03^{\mathrm{a}}$ & $7.44 \pm 0.37^{\mathrm{a}}$ & $6.76 \pm 0.02^{\mathrm{a}}$ \\
\hline & $\mathrm{BL} / \mathrm{HL}$ & $3.75 \pm 0.32^{\mathrm{a}}$ & $3.96 \pm 0.03^{\mathrm{a}}$ & $3.93 \pm 0.32^{\mathrm{a}}$ & $3.95 \pm 0.30^{\mathrm{a}}$ & $4.03 \pm 0.19^{\mathrm{a}}$ & $4.05 \pm 0.08^{\mathrm{a}}$ \\
\hline & $\mathrm{APB} / \mathrm{PoPB}$ & $0.50 \pm 0.05^{\mathrm{a}}$ & $0.47 \pm 0.01^{\mathrm{a}}$ & $0.53 \pm 0.04^{\mathrm{a}}$ & $0.52 \pm 0.06^{\mathrm{a}}$ & $0.50 \pm 0.04^{\mathrm{a}}$ & $0.48 \pm 0.01^{\mathrm{a}}$ \\
\hline & $\mathrm{APB} / \mathrm{BD} 1$ & $3.89 \pm 1.01^{\mathrm{a}}$ & $3.43 \pm 0.37^{\mathrm{a}}$ & $3.66 \pm 0.28^{\mathrm{a}}$ & $3.84 \pm 0.06^{\mathrm{a}}$ & $4.01 \pm 0.45^{\mathrm{a}}$ & $3.65 \pm 0.35^{\mathrm{a}}$ \\
\hline & $\mathrm{APB} / \mathrm{BD} 2$ & $2.51 \pm 0.37^{\mathrm{a}}$ & $2.27 \pm 0.03^{\mathrm{a}}$ & $2.33 \pm 0.12^{\mathrm{a}}$ & $2.38 \pm 0.19^{\mathrm{a}}$ & $2.53 \pm 0.16^{\mathrm{a}}$ & $2.19 \pm 0.05^{\mathrm{a}}$ \\
\hline & $\mathrm{APB} / \mathrm{HL}$ & $1.26 \pm 0.02^{\mathrm{a}}$ & $1.28 \pm 0.02^{\mathrm{c}}$ & $1.35 \pm 0.02^{\mathrm{c}}$ & $1.35 \pm 0.01^{\mathrm{ab}}$ & $1.37 \pm 0.04^{\mathrm{c}}$ & $1.31 \pm 0.00^{\mathrm{bc}}$ \\
\hline & PoPB/BD1 & $7.69 \pm 1.21^{\mathrm{a}}$ & $7.25 \pm 0.58^{\mathrm{a}}$ & $6.94 \pm 0.08^{\mathrm{a}}$ & $7.46 \pm 0.73^{\mathrm{a}}$ & $8.02 \pm 0.60^{\mathrm{a}}$ & $7.65 \pm 0.96^{\mathrm{a}}$ \\
\hline & PoPB/BD2 & $4.99 \pm 0.21^{\mathrm{a}}$ & $4.80 \pm 0.06^{\mathrm{a}}$ & $4.43 \pm 0.37^{\mathrm{a}}$ & $4.65 \pm 0.89^{\mathrm{a}}$ & $5.09 \pm 0.65^{\mathrm{a}}$ & $4.59 \pm 0.03^{\mathrm{a}}$ \\
\hline & $\mathrm{PoPB} / \mathrm{HL}$ & $2.52 \pm 0.30^{\mathrm{a}}$ & $2.71 \pm 0.03^{\mathrm{a}}$ & $2.57 \pm 0.27^{\mathrm{a}}$ & $2.62 \pm 0.32^{\mathrm{a}}$ & $2.75 \pm 0.24^{\mathrm{a}}$ & $2.75 \pm 0.08^{\mathrm{a}}$ \\
\hline & $\mathrm{BD} 1 / \mathrm{BD} 2$ & $0.66 \pm 0.08^{\mathrm{a}}$ & $0.67 \pm 0.06^{\mathrm{a}}$ & $0.64 \pm 0.05^{\mathrm{a}}$ & $0.62 \pm 0.06^{\mathrm{a}}$ & $0.63 \pm 0.07^{\mathrm{a}}$ & $0.61 \pm 0.07^{\mathrm{a}}$ \\
\hline & $\mathrm{BD} 1 / \mathrm{HL}$ & $0.33 \pm 0.09^{\mathrm{a}}$ & $0.38 \pm 0.03^{\mathrm{a}}$ & $0.37 \pm 0.04^{\mathrm{a}}$ & $0.35 \pm 0.01^{\mathrm{a}}$ & $0.34 \pm 0.04^{\mathrm{a}}$ & $0.36 \pm 0.04^{\mathrm{a}}$ \\
\hline & $\mathrm{BD} 2 / \mathrm{HL}$ & $0.51 \pm 0.08^{\mathrm{a}}$ & $0.56 \pm 0.00^{\mathrm{a}}$ & $0.58 \pm 0.04^{\mathrm{a}}$ & $0.57 \pm 0.04^{\mathrm{a}}$ & $0.54 \pm 0.05^{\mathrm{a}}$ & $0.60 \pm 0.01^{\mathrm{a}}$ \\
\hline
\end{tabular}

Mean \pm SD, different superscript letters indicate significant differences. Number of specimens $(n)$ for SR and MCs are 200 and 6 , respectively. A combination of alive microalgae (ACV, ASO, and AHP) and LAN (i.e., ACV+LAN, ASO+LAN, and AHP+LAN), and a combination of lyophilized microalgae (LCV, LSO, and LHP) and LAN (i.e., LCV+LAN, LSO+LAN, and LHP+LAN). See the legend of Figure 2 for abbreviations of the MCs.

(Fig. 6A), the highest expression level was observed in ALG (4.25-fold), followed by YOLK (2.18), ALG+LAN (1.87), and LAN (1.10) food groups.

An increased expression level of $i g f 2 a$ was observed in all food groups relative to the control (10-176-fold). A remarkable variation among the larvae fed on different food groups concerning igf $2 a$ expression level (Fig. 6C) in a way that the highest igf $2 a$ expression level was observed in ALG (175.98fold) followed by ALG+LAN (162.39), YOLK (152.38), LAN (102.66), and SAT (9.59) was observed.

$\mathrm{SR}$ at $11 \mathrm{dpf}$ was significantly correlated to vegfaa expression in the form of a linear function (Fig. 6B), whereas no correlation was found with igf $2 a$. A significant association was observed between igf $2 a$ and MCs at $11 \mathrm{dpf}$ [APB (Fig. 6D), BL/HL (Fig. 6E), BL/APB (Fig. 6F), and PoPB/HL (Fig. 6G)] in the form of quadratic functions, whereas such relationships could not be found with igf $2 a$.

\section{Discussion}

Although no significant differences were found in the HR (Table 4) of the embryos cultured with different microalgae, an earlier hatching at days 2 and 3 (72-96 hpf) was observed, when compared to the eggs incubated with water. Early hatching has been cited as an important stress response of fish larvae $^{55}$ and similar changes in hatching events have been cited in embryos exposed to nanoparticles ${ }^{56-58}$ and crude oil extracts. ${ }^{59}$ Hatching is a consequence of the production of hatching enzymes and embryo movements. ${ }^{60,61}$ In the case of nanoparticles, they tend to adhere to the surface of the egg chorion, blocking the pores that facilitate oxygen exchange and waste elimination, ${ }^{62-64}$ whereas crude oil extracts cause an increase in respiration and gill ventilation rates in the embryo, which facilitates an early rupture and release of hatching enzymes from the glands. ${ }^{59}$ In this study, the change in hatching time (Table 4) can be attributed to the effect of organic acids produced by the algae on egg shell.

The early hatched embryos obtained were smaller in size and with larger yolk sacs relative to body size, indicating that the early hatching is not a result of a faster embryogenesis, but a consequence of premature hatching. ${ }^{57,58}$ However, this early hatching did not affect larval SR at different developmental stages (Tables 5 and 6).

The lowest SR was observed in ALG-fed larvae (Fig. 3B-E), all the larvae died on day 11 postfertilization (Fig. 3E). The presence of ALG in the digestive tract of the ALG-fed larvae 

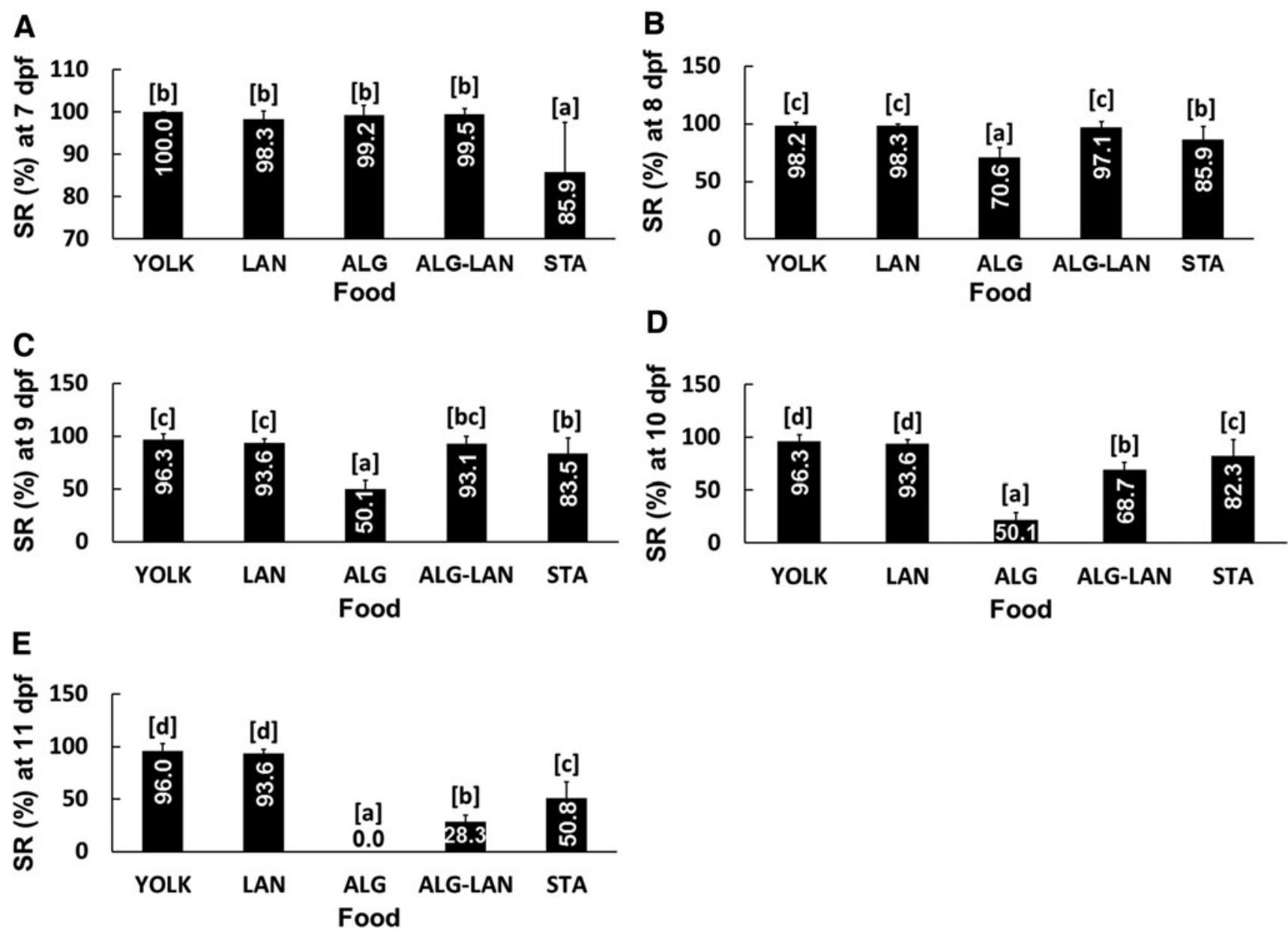

FIG. 3. Results in SR of zebrafish larvae at different days postfertilization. Different letters indicate significant differences among the groups (analysis of variance; $p<0.05$ ). ALG, algae; LAN, lyophilized Artemia nauplii; SR, survival rate; STA, starved; YOLK, egg yolk.

(Fig. 7A), as well as the observation of larvae releasing fecal droppings (Fig. 7B), confirms that they have fed actively on ALG, indicating that ALG are appropriate in size and attractive for zebrafish first-feeding larvae, so the mortality of the larvae (Fig. 3E) cannot be attributed to the failure in feeding on ALG.

The dead larvae fed on ALG had an emaciated appearance similar to that of STA larvae (Fig. 7C). In the ALG-fed larvae, the activity of digestive enzymes such as amylase (Fig. 4A) and lipase (Fig. 4B) started to increase on day 8, reached a maximum level through days 9-10, and decreased, to a level similar to that of STA larvae, on day 11, the day on which all the emaciated ALG-fed larvae died. The significant increase in the activity of the digestive enzymes in ALG-fed larvae compared to STA larvae shows a remarkable endeavor in ALG-fed larvae to digest the ingested ALG. The emaciation of the dead ALG-fed larvae can be related to the failure in ALG digestion. Zebrafish is an omnivorous species with both cellulose-degrading and protease-producing gut microbiome. ${ }^{65}$ However, it might be the case that at early larval stages, the cellulolytic enzyme-producing bacterial community has not been established in the gastrointestinal tract of zebrafish. Yokoe and Yasumasu ${ }^{66}$ mentioned that fish does not possess endogenous cellulose and therefore cellulose digestion depends on the exogenous cellulose produced by microbiota.

The activity of amylase (Fig. 4A) and lipase (Fig. 4B) in ALG-fed larvae was also higher than LAN-fed larvae, whereas the alkaline protease activity detected in the LANfed larvae (Fig. 4C) was not observed in ALG-fed larvae. The qualitative and quantitative variation in digestive enzyme profile in fish have already been asserted to feed type, quality (digestibility), and nutritional status. ${ }^{67}$ In the young carps, the activity of digestive enzymes showed an adaptation to a dietary change within a week. ${ }^{68}$

All the ALG-fed larvae died on day 11 postfertilization, earlier than STA larvae (Fig. 3e). This accelerated mortality compared to STA larvae can be associated to the dramatic amount of energy spent by ALG-fed larvae to digest ALG.

To understand the early death of ALG-fed larvae, several factors of ALG-related products were analyzed. ALG excretions were excluded as one of the causes of early death of the larvae, having in mind the frequent washing of harvested ALG (see Preparation of ALG Culture and Suspension section). Other factors such as ALG-related endotoxins, such as 


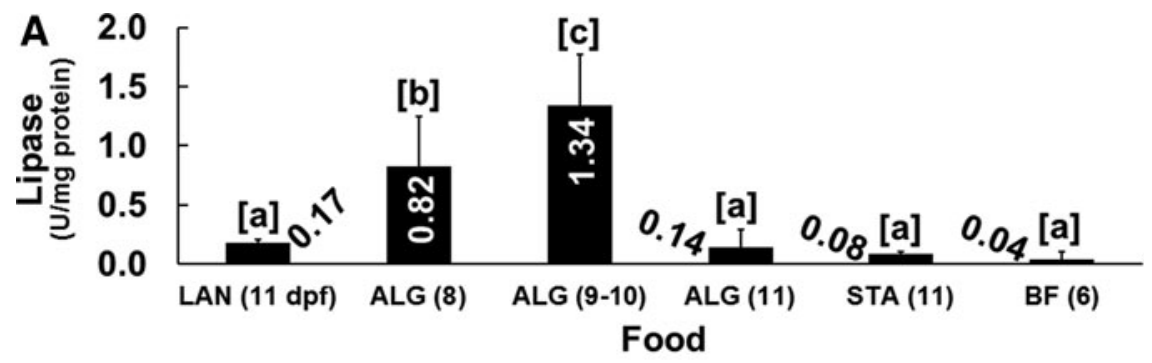

FIG. 4. Digestive enzyme activities in zebrafish larvae. (A) Lipase, (B) amylase, (C) alkaline activity. ALG, algae; BF, before active feeding; STA, starved, YOLK, egg yolk. Results that do not share the same letter are significantly different.
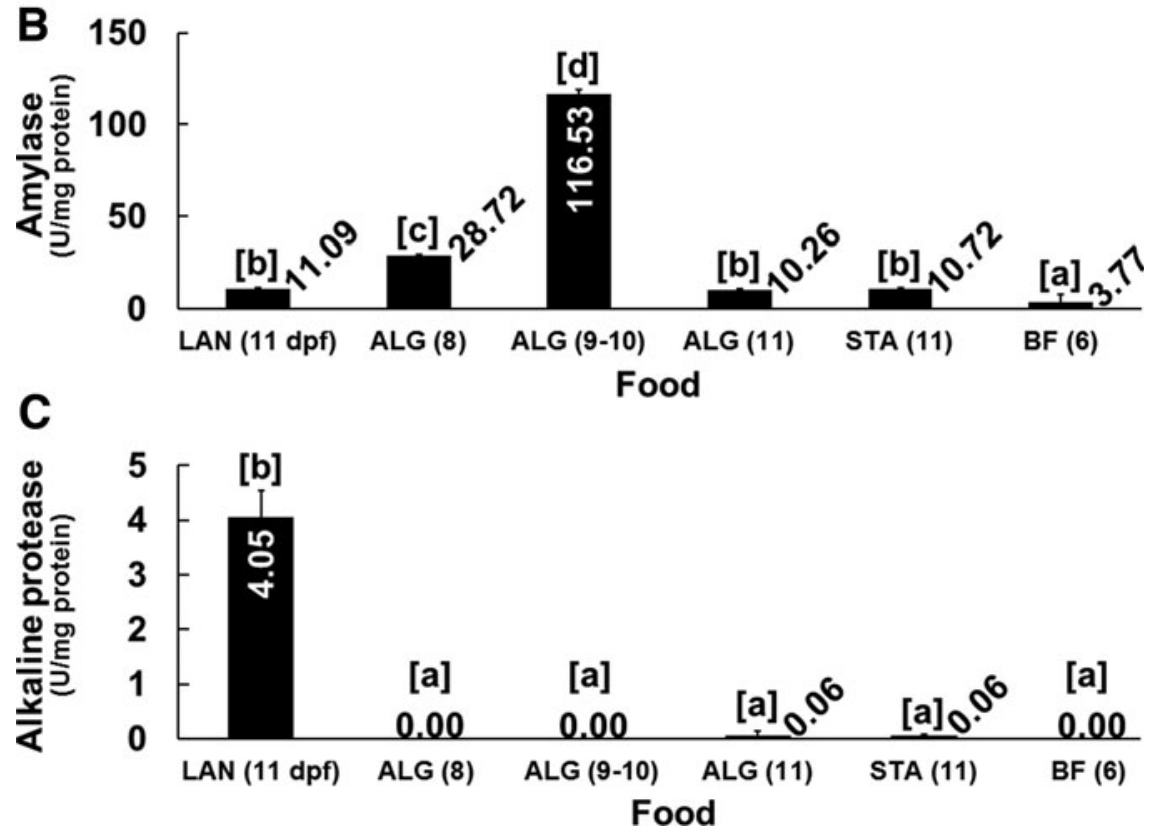

larvicides, cytotoxins, nematicides, pesticides, and antioxidants, were analyzed (data not shown) without finding any difference in larval survival (Table 5) fed on ALG containing different phytochemical profile. Thus, the early death of zebrafish larvae cannot be attributed to ALG-related products. Furthermore, distilled water was used to prepare ALG medium to avoid any possibility of water contamination (i.e., heavy metals or other toxic products)

The premature death of the ALG-fed larvae might also be related to the nutritional composition of the ALG. However, the amounts of essential polyunsaturated fatty acids (PUFAs) such as 18:2n-6 (linoleic acid) and 18:3n-3 (alpha-linolenic acid) in ALG (Table 3, rows 15 and 17, respectively) are higher compared with Artemia. Zebrafish can convert these two FAs to longer and more unsaturated homologs (highunsaturated FA) such as 20:4n-6, 20:5n-3, and 22:6n-3. ${ }^{69-71}$ On the other hand, larvae fed on Spirulina with an FA profile (Table 3, column 7) similar to that of $C V, S O$, and $H P$ (Table 3, columns 4, 5, and 6, respectively) and a higher protein content $(73.10 \% \pm 1.04 \%)$ had an SR (data not shown) comparable to that of $C V$-, SO-, and $H P$-fed larvae. Considering all this information, the low SR at different dpf (Fig. 3B-E) in the ALG-fed larvae compared to STA larvae (Fig. 3), the malnutrition-related early death should be rejected.

Microalgae species used in aquaculture are not equally successful in supporting the growth and survival of a particular fish. Suitable ALG species have been selected on the basis of their mass-culture potential, cell size, digestibility, and overall food value for a feeding animal. ${ }^{34}$ In our laboratory, the three freshwater ALG $(C V, S O$, and $H P)$ are used to feed $B$. orientalis, and their mass-culture protocols are available. ${ }^{35-37}$ The presence of ALG in the digestive tract of the larvae (Fig. 7A, B) indicates that they have an appropriate size and are attractive to the larvae. The high essential FA content in $C V, S O, H P$, and Spirulina sp. $(S P)$ compared to AN (Table 3), as well as the high protein content of $S P$ $(73.10 \%)$ also show the overall good nutritional value of ALG. Thus, the low SR and early death of zebrafish larvae in this study can only be attributed to the low or nil digestibility of ALG $(C V, S O, H P$, and $S P)$ in first-feeding larvae.

The highest larval SR ( $>90 \%)$ was obtained in LAN- and YOLK-fed groups at all days postfertilization (Fig. 3). No significant differences between LAN- and YOLK-fed larvae were detected in SR and no differences could be found in SR on day 7 to 11 . These results highlight the potential of these two simple feeds to support zebrafish early larval success. In at least one early report by Carvalho et al., ${ }^{7} \mathrm{AN}$ have been shown to support high growth and survival as a first-feeding item for zebrafish, but in practice, this is difficult because the nauplii are often too large and too fast to be captured and ingested by first-feeding zebrafish larvae. ${ }^{23}$ The results of this study show that LAN can be used as an alternative to address these shortcomings. Takahashi ${ }^{72}$ used a combination of YOLK (suspended daily in the rearing water) and live freshwater copepods to raise zebrafish larvae in an early growth period of about 10 days after hatching. 
Table 7. Comparison Among Zebrafish Larvae Fed on Different Food Groups Concerning Morphometric CharaCteristics ON DAY 11

\begin{tabular}{|c|c|c|c|c|c|}
\hline \multirow[b]{2}{*}{$M C s$} & \multicolumn{5}{|c|}{ Food groups } \\
\hline & $Y O L K$ & $L A N$ & $A L G$ & $A L G+L A N$ & $S T A$ \\
\hline BL & $3.79 \pm 0.25^{\mathrm{ab}}$ & $3.83 \pm 0.25^{\mathrm{ab}}$ & $3.67 \pm 0.15^{\mathrm{a}}$ & $3.70 \pm 0.20^{\mathrm{ab}}$ & $3.89 \pm 0.06^{\mathrm{b}}$ \\
\hline HL & $1.07 \pm 0.13^{\mathrm{b}}$ & $1.08 \pm 0.14^{\mathrm{b}}$ & $0.92 \pm 0.07^{\mathrm{a}}$ & $0.94 \pm 0.08^{\mathrm{a}}$ & $0.85 \pm 0.03^{\mathrm{a}}$ \\
\hline APB & $1.35 \pm 0.18^{\mathrm{c}}$ & $1.38 \pm 0.18^{\mathrm{c}}$ & $1.21 \pm 0.07^{\mathrm{a}}$ & $1.24 \pm 0.10^{\mathrm{ab}}$ & $1.33 \pm 0.01^{b c}$ \\
\hline PoPB & $2.42 \pm 0.04^{\mathrm{a}}$ & $2.46 \pm 0.09^{\mathrm{ab}}$ & $2.45 \pm 0.12^{\mathrm{ab}}$ & $2.49 \pm 0.14^{\mathrm{ab}}$ & $2.56 \pm 0.05^{\mathrm{b}}$ \\
\hline BD1 & $0.38 \pm 0.07^{\mathrm{c}}$ & $0.35 \pm 0.01^{\mathrm{b}}$ & $0.33 \pm 0.02^{\mathrm{ab}}$ & $0.33 \pm 0.03^{\mathrm{ab}}$ & $0.31 \pm 0.00^{\mathrm{a}}$ \\
\hline $\mathrm{BD} 2$ & $0.56 \pm 0.10^{\mathrm{bc}}$ & $0.57 \pm 0.07^{\mathrm{c}}$ & $0.49 \pm 0.03^{\mathrm{a}}$ & $0.52 \pm 0.05^{\mathrm{ab}}$ & $0.49 \pm 0.00^{\mathrm{a}}$ \\
\hline $\mathrm{BL} / \mathrm{APB}$ & $2.82 \pm 0.19^{\mathrm{a}}$ & $2.79 \pm 0.19^{\mathrm{a}}$ & $3.03 \pm 0.12^{\mathrm{b}}$ & $2.99 \pm 0.13^{\mathrm{b}}$ & $2.93 \pm 0.02^{\mathrm{ab}}$ \\
\hline $\mathrm{BL} / \mathrm{PoPB}$ & $1.57 \pm 0.10^{\mathrm{b}}$ & $1.56 \pm 0.06^{\mathrm{b}}$ & $1.50 \pm 0.03^{\mathrm{a}}$ & $1.49 \pm 0.06^{\mathrm{a}}$ & $1.52 \pm 0.01^{\mathrm{ab}}$ \\
\hline $\mathrm{BL} / \mathrm{BD} 1$ & $10.05 \pm 1.33^{\mathrm{a}}$ & $10.99 \pm 0.88^{\mathrm{ab}}$ & $11.29 \pm 0.82^{\mathrm{b}}$ & $11.30 \pm 1.00^{\mathrm{b}}$ & $12.49 \pm 0.15^{\mathrm{c}}$ \\
\hline $\mathrm{BL} / \mathrm{BD} 2$ & $6.81 \pm 0.71^{\mathrm{a}}$ & $6.75 \pm 0.58^{\mathrm{a}}$ & $7.45 \pm 0.53^{\mathrm{ab}}$ & $7.15 \pm 0.48^{\mathrm{bc}}$ & $7.99 \pm 0.14^{\mathrm{c}}$ \\
\hline $\mathrm{BL} / \mathrm{HL}$ & $3.55 \pm 0.24^{\mathrm{a}}$ & $3.56 \pm 0.24^{\mathrm{a}}$ & $4.02 \pm 0.23^{\mathrm{b}}$ & $3.96 \pm 0.22^{\mathrm{b}}$ & $4.60 \pm 0.13^{\mathrm{c}}$ \\
\hline $\mathrm{APB} / \mathrm{PoPB}$ & $0.56 \pm 0.07^{b}$ & $0.56 \pm 0.06^{\mathrm{b}}$ & $0.50 \pm 0.03^{\mathrm{a}}$ & $0.50 \pm 0.04^{\mathrm{a}}$ & $0.52 \pm 0.01^{\mathrm{ab}}$ \\
\hline $\mathrm{APB} / \mathrm{BD} 1$ & $3.56 \pm 0.31^{\mathrm{a}}$ & $3.96 \pm 0.55^{\mathrm{ab}}$ & $3.74 \pm 0.32^{\mathrm{a}}$ & $3.80 \pm 0.42^{\mathrm{a}}$ & $4.26 \pm 0.03^{\mathrm{a}}$ \\
\hline $\mathrm{APB} / \mathrm{BD} 2$ & $2.41 \pm 0.10^{\mathrm{a}}$ & $2.42 \pm 0.18^{\mathrm{a}}$ & $2.47 \pm 0.22^{\mathrm{a}}$ & $2.40 \pm 0.20^{\mathrm{a}}$ & $2.72 \pm 0.04^{\mathrm{b}}$ \\
\hline $\mathrm{APB} / \mathrm{HL}$ & $1.26 \pm 0.08^{\mathrm{a}}$ & $1.28 \pm 0.07^{\mathrm{a}}$ & $1.33 \pm 0.06^{\mathrm{a}}$ & $1.33 \pm 0.05^{\mathrm{a}}$ & $1.57 \pm 0.04^{\mathrm{b}}$ \\
\hline PoPB/BD1 & $6.45 \pm 1.13^{\mathrm{a}}$ & $7.06 \pm 0.44^{\mathrm{ab}}$ & $7.55 \pm 0.58^{b c}$ & $7.60 \pm 0.68^{b c}$ & $8.23 \pm 0.13^{c}$ \\
\hline PoPB/BD2 & $4.37 \pm 0.69^{\mathrm{a}}$ & $4.35 \pm 0.51^{\mathrm{a}}$ & $4.97 \pm 0.35^{\mathrm{b}}$ & $4.81 \pm 0.45^{\mathrm{ab}}$ & $5.26 \pm 0.11^{b}$ \\
\hline PoPB/HL & $2.28 \pm 0.27^{\mathrm{a}}$ & $2.29 \pm 0.22^{\mathrm{a}}$ & $2.69 \pm 0.18^{\mathrm{b}}$ & $2.67 \pm 0.21^{\mathrm{b}}$ & $3.03 \pm 0.09^{c}$ \\
\hline $\mathrm{BD} 1 / \mathrm{BD} 2$ & $0.68 \pm 0.04^{\mathrm{b}}$ & $0.62 \pm 0.07^{\mathrm{a}}$ & $0.66 \pm 0.05^{\mathrm{ab}}$ & $0.64 \pm 0.05^{\mathrm{ab}}$ & $0.64 \pm 0.00^{\mathrm{ab}}$ \\
\hline $\mathrm{BD} 1 / \mathrm{HL}$ & $0.36 \pm 0.05^{\mathrm{a}}$ & $0.33 \pm 0.05^{\mathrm{a}}$ & $0.36 \pm 0.03^{\mathrm{a}}$ & $0.35 \pm 0.04^{\mathrm{a}}$ & $0.37 \pm 0.01^{\mathrm{a}}$ \\
\hline $\mathrm{BD} 2 / \mathrm{HL}$ & $0.52 \pm 0.05^{\mathrm{a}}$ & $0.53 \pm 0.07^{\mathrm{a}}$ & $0.54 \pm 0.05^{\mathrm{a}}$ & $0.56 \pm 0.05^{\mathrm{a}}$ & $0.58 \pm 0.02^{\mathrm{a}}$ \\
\hline
\end{tabular}

Data are mean \pm SD. Mean values within horizontal rows superscripted by the same letter are not significantly different. Number of specimens $(n)$ for MCs is 6 . See the legend of Figure 2 for abbreviations of the MCs. BL: largest horizontal body distance-anterior part of the head to the end of the body. APB: anterior part of the head to the posterior insertion of yolk sac. PoPB: the posterior insertion of yolk sac to the end of the body. HL: anterior part of the head to the place where the head is connected to the body. BD1: vertical distance from posterior insertion of yolk sac to the upper surface of the body. BD2: largest vertical body distance. Fifteen ratios were calculated from the six MCs and included in Tables 6 and 7 BL/APB, BL/PoPB, BL/BD1, BL/BD2, BL/HL, APB/PoPB, APB/BD1, APB/BD1, APB/HL, PoPB/BD1, PoPB/BD2, PoPB/HL, BD1/BD2, BD1/HL, and BD1/HL.

ALG, alga; APB, anterior part of the body; BD1, body depth 1; BD2, body depth 2; BL, total body length; HL, head length; LAN, lyophilized Artemia nauplii; PoPB, posterior part of body; STA, starved; YOLK, egg yolk.

Adding LAN (50\%) to ALG-fed larvae led to an increase in the SR of this ALG+LAN-fed larvae compared to ALG-fed group, although a significant decline in SR of ALG-LAN-fed larvae from day 7 to 11 was observed (Fig. 3). In the case of ALG-fed larvae, all the larvae died on day 11, while ALG+LAN-fed larvae had an SR of $28 \%$. Kawai and Ikeda $^{68}$ reported that the protein digestibility of a diet with different cellulose levels did not show differences, although the growth rate decreased in accordance with the increase in cellulose content contrary to the results of our study where the presence of ALG in the ALG+LAN-fed larvae led to a significant decline in SR compared to LAN-fed larvae.

The results obtained in this study show food-dependent changes in the MCs of the larvae (Table 7). Morphometric based assays are considered relevant to study fish larval growth and developmental response to several agents, ${ }^{73}$ such as nanomaterials, ${ }^{58,74}$ drugs, ${ }^{75}$ and endocrine-disrupting chemicals. ${ }^{76} \mathrm{MCs}$ are used to assess the impact on larval growth and development when they are exposed to concentrations well below those that change larval survival or produce an increase in malformations (Prof. Dr. Jennifer L. Freeman, Purdue University, pers. comm.). Thus, the significant variations of MCs detected among larvae fed on different types of feed (Table 7) evidence that MCs can be efficiently used to characterize diet-induced changes in larval growth and development.
Regarding the MCs (Fig. 5), the largest anterior part of the body was observed in larvae from LAN and YOLK groups followed by STA and ALG+LAN- and ALG-fed ones. Fish growth delay is often related to starvation or malnutrition ${ }^{77,78}$ and these can be the reasons of the smaller size of the anterior part of the body observed in STA, ALG+LAN-, and ALG-fed larvae. The size of the anterior part of body is a determinant factor for larvae to shift on $\mathrm{AN}$ in zebrafish, leaving behind a critical larval stage.

No significant difference in SR could be found between LAN- and YOLK-fed larvae, although LAN group started to feed on AN sooner. This can be attributed to the bigger size of the anterior part of body in the LAN-fed larvae compared to YOLK-fed larvae. In other words, feeding with LAN accelerated larval growth. The high energy-protein ratio of YOLK as a diet for very young fish could result in an inadequate protein intake necessary for maximal growth, ${ }^{79}$ explaining the smaller anterior part of body in YOLK-fed larvae. On the other hand, the presence of digestive enzymes in AN has led to the speculation ${ }^{80}$ that these exogenous enzymes can play a significant role in the breakdown of the nauplii in the digestive tract of larvae. Thus, the relatively low levels of digestive enzymes in first-feeding larvae and subsequently the decrease in the digestion energy expenditure can contribute to the bigger size of the anterior part of body in LAN-fed larvae. 


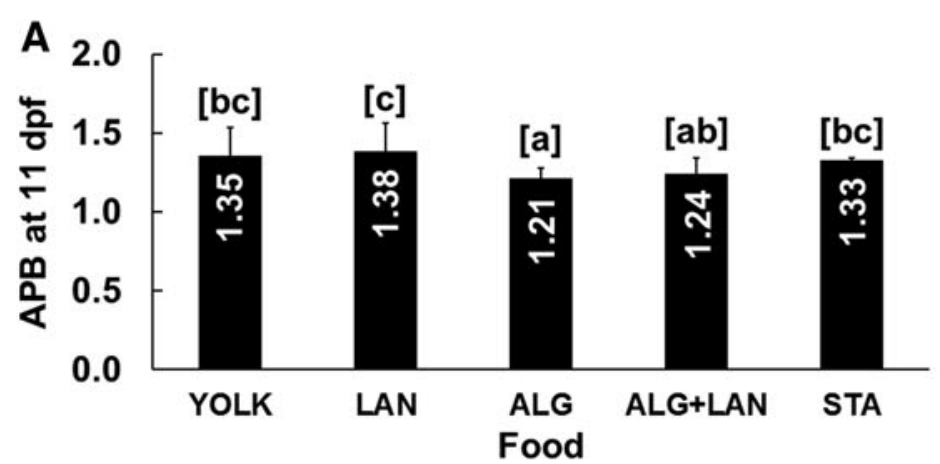

B
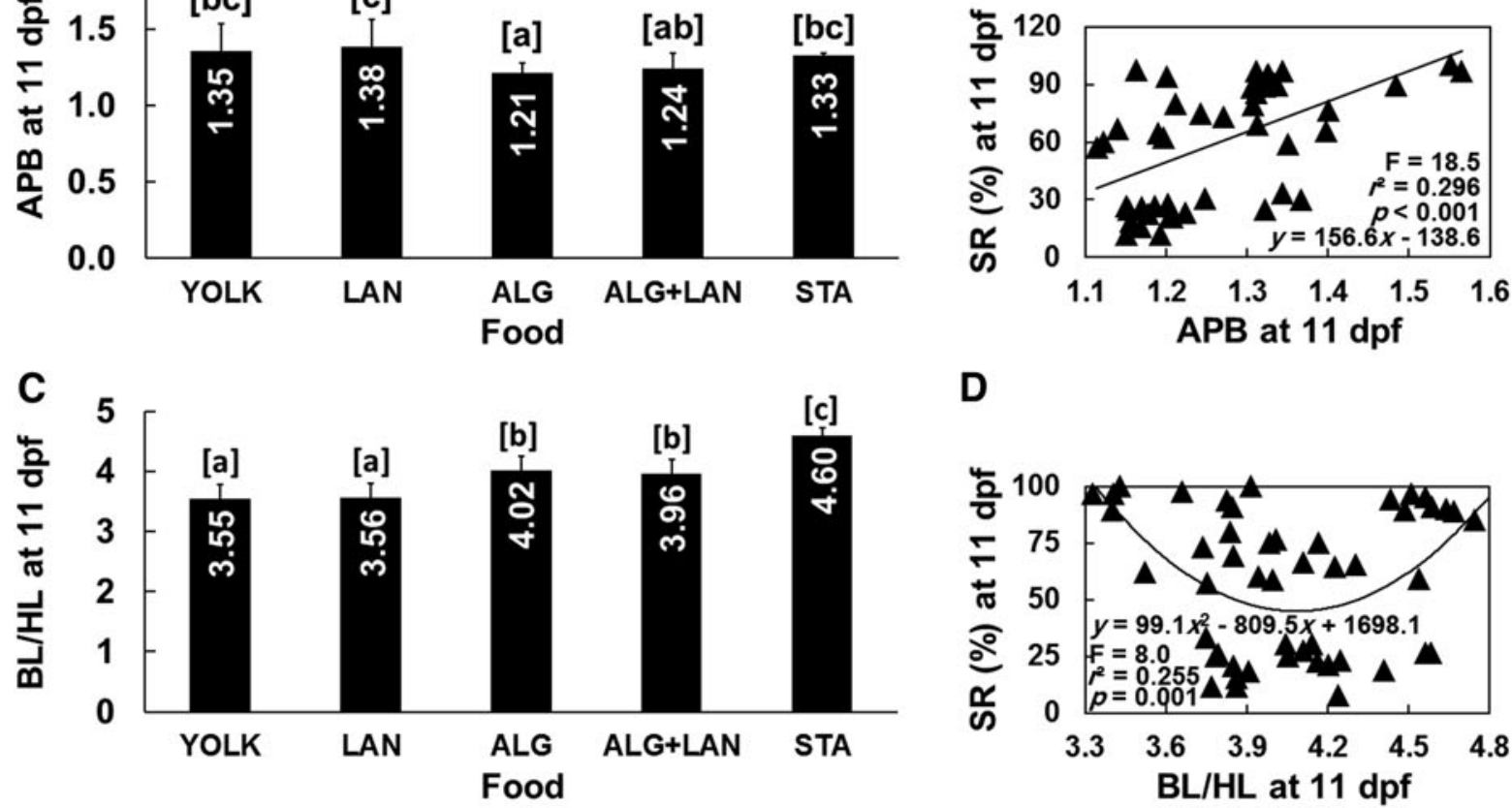

D

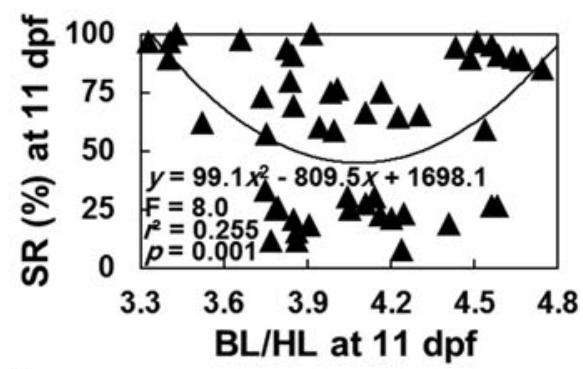

E

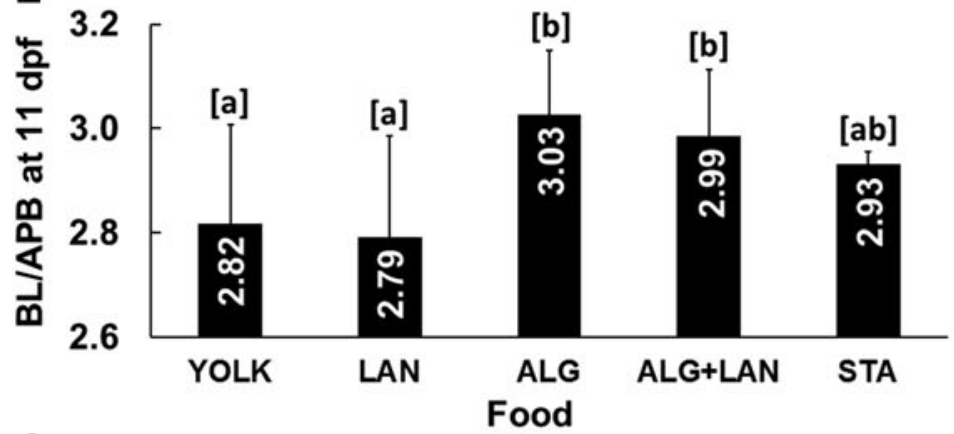

$\mathbf{F}$

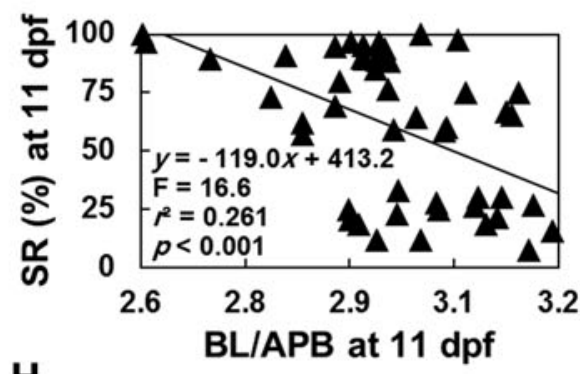

H
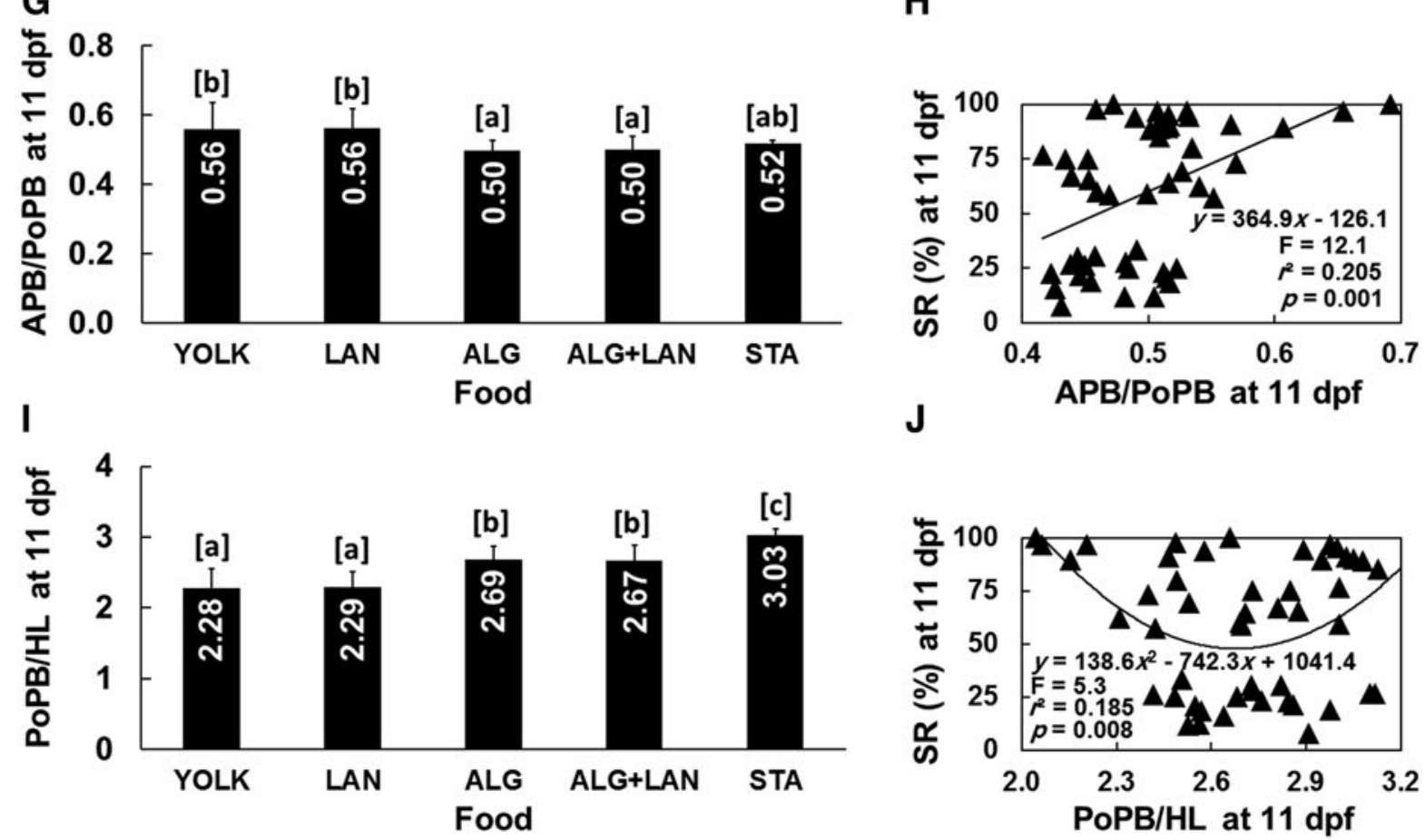

FIG. 5. Variation among food groups concerning MCs at $11 \mathrm{dpf}(\mathbf{A}, \mathbf{C}, \mathbf{E}, \mathbf{G}, \mathbf{I})$. Results that do not share the same letter are significantly different. Scatter plots show significant relationships between SR at $11 \mathrm{dpf}$ (as dependent variables) and MCs at $11 \mathrm{dpf}$ (as the independent variable) (B, D, F, H, J). ALG, algae; STA, starved; YOLK, egg yolk. See the legend of Figure 2 for abbreviations of MCs. 
A
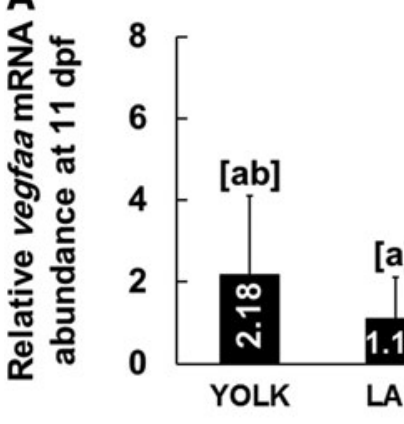

C

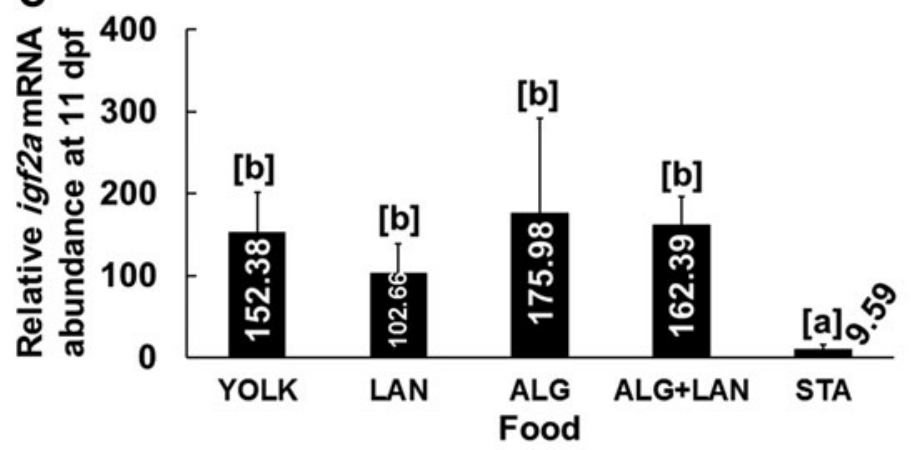

E

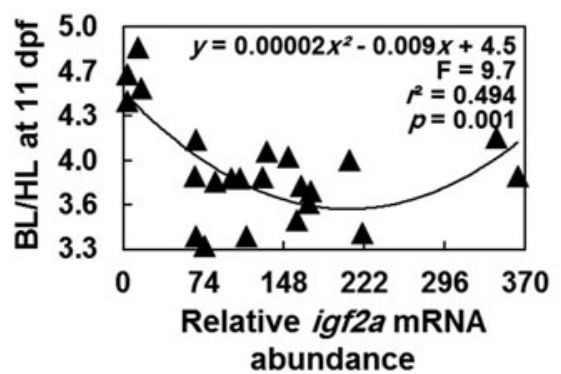

[b]

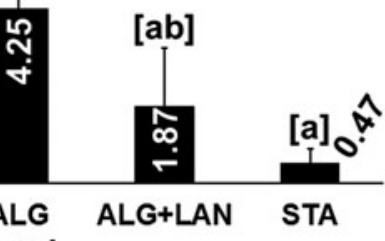

ALG
Food

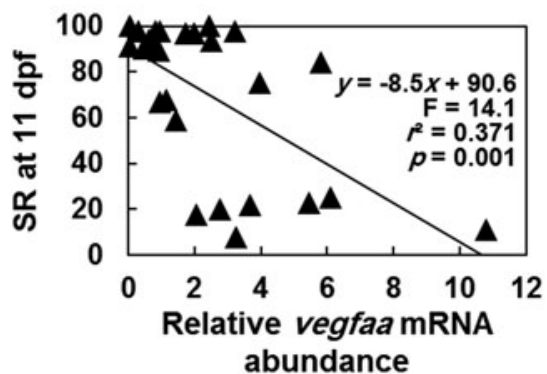

D

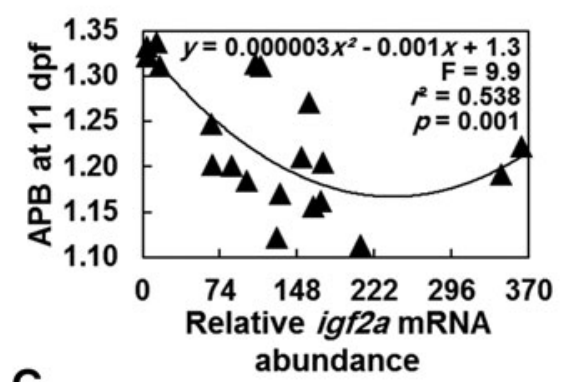

G

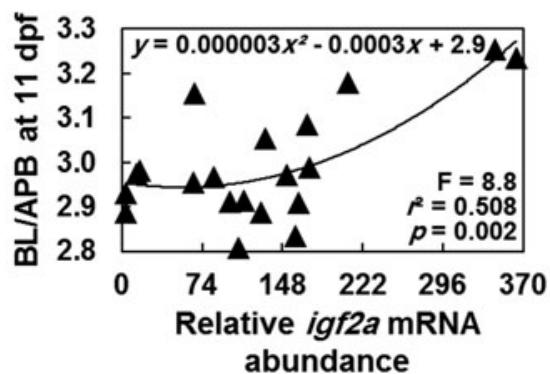

FIG. 6. Variation among food groups concerning the expression level of vegfaa (A) and igf $2 a(\mathbf{C})$ at 11 dpf. Results that do not share the same letter are significantly different. Scatter plot shows significant relationships between SR at $11 \mathrm{dpf}$ (as dependent variables) and vegfaa at $11 \mathrm{dpf}$ (as the independent variable) (B). Scatter plots show significant relationships between MCs at $11 \mathrm{dpf}$ (as dependent variables) and $i g f 2 a$ at $11 \mathrm{dpf}$ (as the independent variable) (D-G). ALG, algae; STA, starved; YOLK, egg yolk. See the legend of Figure 2 for abbreviations of MCs.

Bahary et al. ${ }^{81}$ isolated a duplicated vegfa locus in zebrafish (denoted as vegfaa and vegfab). Transfection of native zebrafish vegfa constructs into mammalian cell lines showed that vegfaa is secreted, but vegfab is not, even though a well-defined signal peptide is present. In this study, a nutritionally induced change in vegfaa expression level in zebrafish larvae at $11 \mathrm{dpf}$ relative to control was observed. The magnitude of the significant variation in vegfaa expression level was food dependent (Fig. 6A). Such responses have also been cited by Chakraborty et al. ${ }^{82}$ when the zebrafish larvae had been exposed to caffeine, norfloxacin, and nimesulide.

The vegfa gene is a highly specific vascular endothelial cell mitogen. ${ }^{83}$ It is the strongest proangiogenic factor in the vegf family and it is expressed in every tissue. ${ }^{84,85}$ The vegf gene family provides signals required for vasculogenesis (de novo formation of blood vessels) during embryogenesis and for angiogenesis (formation of new blood vessels from preexisting vessels) during organogenesis. ${ }^{44}$ In this study, a significant association between SR at $11 \mathrm{dpf}$ and vegfaa expression was observed (Fig. 6B), being SR variations (Fig. 3) supported by changes at molecular levels (Fig. 6A).

$i g f \mathrm{~s}$ are evolutionarily ancient growth factors present in all vertebrates. ${ }^{86}$ It comprises four exons spanning $5981 \mathrm{bp}$ on chromosome $7{ }^{87}$ The igf $2 a$ acts through a conserved signaling pathway that regulates growth, development, metabolism, and longevity in a wide variety of animals. ${ }^{37}$ In zebrafish, mRNA expression of the igf $2 a$ is observed in embryonic. ${ }^{86,88}$ The nutritionally induced changes in igf $2 a$ expression level in zebrafish larvae at $11 \mathrm{dpf}$ in this study (Fig. 6C) is consistent with early studies such as those by Chauvigné et al. ${ }^{89}$ who cited an increased igf 2 expression in refed juvenile rainbow trout after prolonged fasting periods, Thissen et $a l^{42}$ observed a glucose-induced rise in igf2 
FIG. 7. Photomicrographs of zebrafish larvae at 8 (A), 9 (B), and $11 \mathrm{dpf}(\mathbf{C})$. The arrows in (A) indicate ingested algae by an 8 dpf zebrafish larva. (B) Algae fed larvae at 9 dpf releasing fecal droppings. (C) Algae fed larvae at $11 \mathrm{dpf}$. dpf, days postfertilization.

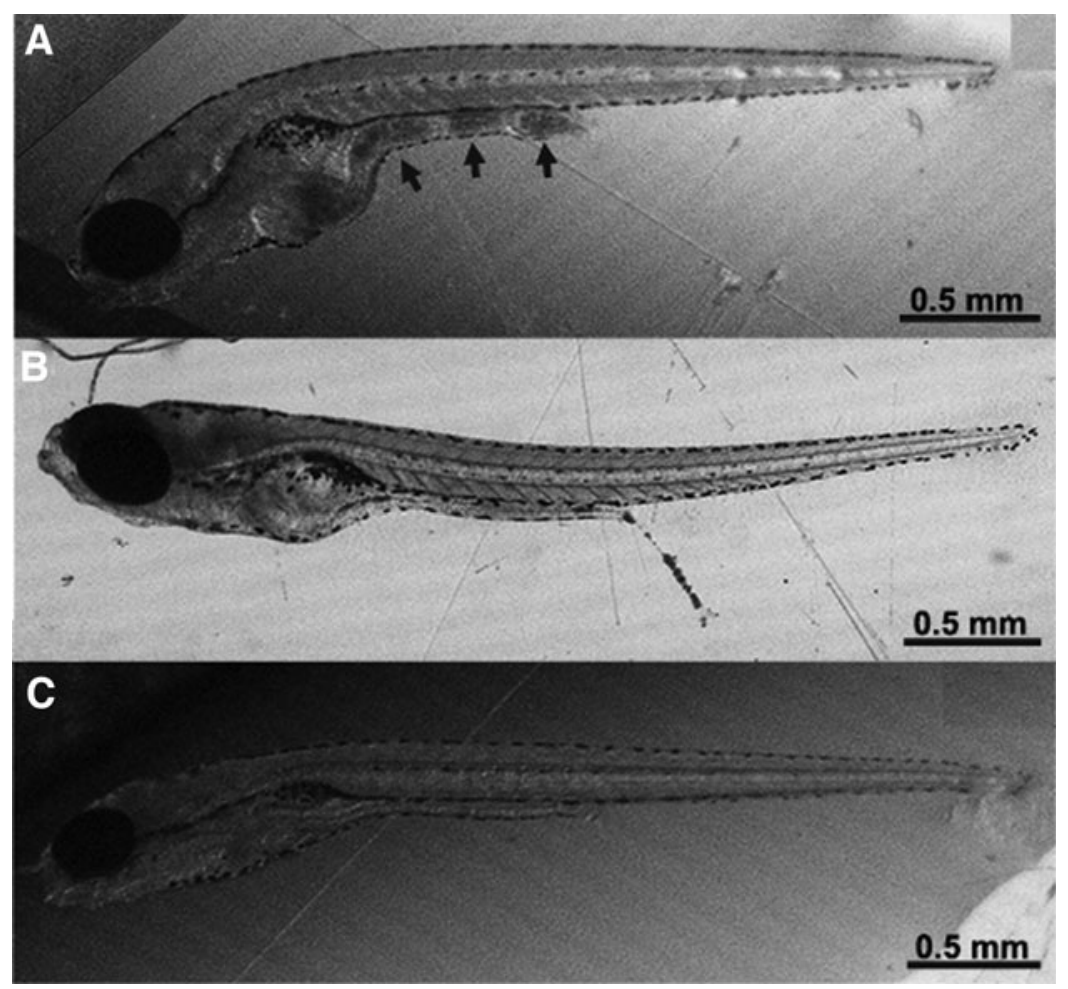

mRNA by stimulation of gene transcription and increased transcript stability, Soliman et al. ${ }^{39}$ cited reduced serum igf2 concentrations in chronically malnourished children, and Straus and Takemoto ${ }^{40}$ observed a decreased igf 2 mRNA in amino acid-deprived rat liver from alterations in posttranscriptional regulatory mechanisms. Thus, nutritional status is an important determining factor in the expression and secretion of metabolic hormones such as insulin family peptides. ${ }^{38}$ In our study, MCs were significantly correlated to igf $2 a$ expression level in zebrafish larvae at $11 \mathrm{dpf}$ (Fig. 6D-G). The igf $2 a$ functions in the dorsal midline tissue during segmentation (defined by somitogenesis, elongation of the anteriorposterior axis, and neurulation-Kimmel et al. $)^{90}$ and during early development. ${ }^{87}$ The igf2 mediates notochord formation and nephron development. ${ }^{91}$ The observed effects are significant because notochord development is a highly conserved aspect of chordate development: the notochord, a transient mesoderm structure, secretes inductive cell signaling factors (e.g., Hedgehog proteins) that promote patterning of adjacent tissues, including the neural tube and somites. ${ }^{87}$ It is clearly evident that igf2 retains importance during posthatching development in teleosts, possibly as a local paracrine and/or autocrine regulator of tissue growth. ${ }^{38}$ Thus, in this study, a significant association was observed between MCs and igf $2 a$ expression (Fig. 6D-G) and the biometric variations (Fig. 5A, C, E, G, I) were supported by changes at molecular levels (Fig. 6C). In the studies of Zarantoniello et al. ${ }^{92}$ in which zebrafish was fed on black soldier fly (BSF)based diets, such biometric variations were not correlated with igf $2 a$ expression level.

ALG were not digestible for zebrafish early larvae and the enzymatic content of $\mathrm{LAN}^{80}$ make them more digestible than YOLK. In other words, digestibility was different depending of the food used. The lowest vegfaa and igf $2 a$ expression was observed in zebrafish larvae fed on more digestible feeds (Fig. 6A, C); Thus, it seems that there is a negative association between feed digestibility and vegfaa and igf $2 a$ expression level.

Carvalho et al. ${ }^{7}$ noted that zebrafish larvae are routinely reared on paramecia during the first 9 days of exogenous feeding, followed by a combination of paramecia and AN until day 21. Varga ${ }^{9}$ cited paramecium from days 5-10, Zeigler AP 100 (a food that is not available) from day 11-12, and AN thereafter. The abovementioned feeding strategies are expensive, labor intensive, and unpredictable. ${ }^{7}$ Feeding of zebrafish larvae with LAN suspension from day 5(6) to 10 and $\mathrm{AN}$ thereafter, the feeding protocol used in this study, is a more simple method to rare first-feeding zebrafish larvae compared to current published methods, especially if zebrafish is maintained in low-cost facilities.

LAN looks a suitable alternative for zebrafish larviculture, although there are some negative points to recruit that for zebrafish low-cost facilities: (1) it is expensive, ${ }^{79}$ (2) strongly contaminates larval culture medium, a problem that is cited for processed feeds as well, ${ }^{6,22}$ which leads to a complete larvae medium exchange after each feeding, a laborious and time-consuming work, (3) it can be a nutritional problem in view of its deficiency in sulfur amino acids, like methionine, ${ }^{80}$ although this can be addressed by combining the LAN with lyophilized adult Artemia to feed first-feeding larvae, and (4) the preparation of LAN needs a freeze-drying system that is not always available in a low-cost facility.

Egg yolk per se is highly nutritious and is unquestionably one of the most nutritionally balanced foods known for man and animals. The fine granular texture of boiled yolk has indeed provided aquaculturists with a practical artificial diet that is superior to most other artificial feeds for this purpose. ${ }^{79}$ In addition, the similar survival and growth rates of 
YOLK- and LAN-fed larvae, together with lacking the abovementioned shortcomings of LAN, uncover the potential of YOLK as a starter food for zebrafish first-feeding larvae in low-cost facilities.

As a conclusion, the results of this study show that ALG, either alone or in combination to LAN (ALG+LAN group), cannot be considered a suitable starter food for zebrafish. YOLK might be recommended as the best one.

\section{Acknowledgments}

The authors are grateful to Dr. Fatemeh Mansouri (Urmia University of Medical Sciences, Iran) for her help to design primers.

\section{Disclosure Statement}

No competing financial interests exist.

\section{Funding Information}

No funding was received for this work.

\section{References}

1. Lawrence C, Best J, Cockington J, Henry EC, Hurley S, James A, et al. The complete and updated "rotifer polyculture method" for rearing first feeding zebrafish. J Vis Exp 2016;107:e53629.

2. Hernandez RE, Galitan L, Cameron J, Goodwin N, Ramakrishnan L. Delay of initial feeding of zebrafish larvae until 8 days postfertilization has no impact on survival or growth through the juvenile stage. Zebrafish 2018;15:515518.

3. Nakayama H, Katayama K, Onabe Y, Sato A, Nishimura N, Shimada Y. Dried rotifer sheet: a novel live feed for rearing first-feeding larvae. Zebrafish 2018;15:291-294.

4. Best J, Adatto S, Cockington J, James A, Lawrence C. A novel method for rearing first-feeding larval zebrafish: polyculture with type L saltwater rotifers (Brachionus plicatilis). Zebrafish 2010;7:289-295.

5. Allen RL, Wallace RL, Sisson BE. A rotifer-based technique to rear zebrafish larvae in small academic settings. Zebrafish 2016;13:281-286.

6. Cahu C, Infante JZ. Substitution of live food by formulated diets in marine fish larvae. Aquaculture 2001;200:161-180.

7. Carvalho AP, Araùjo L, Santos MM. Rearing zebrafish (Danio rerio) larvae without live food: evaluation of a commercial, a practical and a purified starter diet on larval performance. Aquac Res 2006;37:1107-1111.

8. Goolish EM, Okutake K, Lesure S. Growth and survivorship of larval zebrafish, Danio rerio, on processed diets. N Am J Aquac 1999;61:189-198.

9. Varga ZM. Aquaculture and husbandry at the zebrafish international resource center. Method Cell Biol 2011;104: 453-478.

10. Lawrence C, Sanders E, Henry E. Methods for culturing saltwater rotifers (Brachionus plicatilis) for rearing larval zebrafish. Zebrafish 2012;9:140-146.

11. Konrad D, Miller M. Contested paradigm in raising zebrafish (Danio rerio). Zebrafish 2018;15:295-309.

12. Aoyama Y, Moriya N, Tanaka S, Taniguchi T, Hosokawa $\mathrm{H}$, Maegawa S. A novel method for rearing zebrafish by using freshwater rotifers (Brachionus calyciflorus). Zebrafish $2015 ; 12: 288-295$.
13. Westerfield M. The Zebrafish Book: A Guide for the Laboratory Use of Zebrafish Danio (branchydanio) rerio, fifth edition. University of Oregon Press, Eugene, OR, 2007.

14. Nusslein-Volhard C, Dahm R. Zebrafish, A Practical Approach. Oxford University Press, Oxford, 2002.

15. Matthews M, Trevarrow B, Matthews J. A virtual tour of the guide for zebrafish users. Lab Anim 2002;31:34-40.

16. Cattin P, Crosier P. A nursery that improves zebrafish fry survival. Methods Cell Biol 2004;77:593-598.

17. Biga P, Goetz F. Zebrafish and giant danio as models for muscle growth: determinate vs. indeterminate growth as determined by morphometric analysis. Am J Physiol Regul Integr Comp Physiol 2006;291:R1327-R1337.

18. Hoff F, Snell T. Plankton Culture Manual, 6th edition. Florida Aqua Farms, Inc., Dade City, FL, 2004.

19. Guidetti R, Jönsson KI. Long-term anhydrobiotic survival in semi-terrestrial micrometazoans. J Zool 2002;257:181187.

20. Farias M, Certal AC. Different feeds and feeding regimens have an impact on zebrafish larval rearing and breeding performance. SOJ Aquatic Res 2016;1:1-8.

21. Monteiro JF, Martins S, Farias M, Costa T, Certal AC. The impact of two different cold-extruded feeds and feeding regimens on zebrafish survival, growth and reproductive performance. J Dev Biol 2018;6:1-14.

22. Hensley MR, Leung YF. A convenient dry feed for raising zebrafish larvae. Zebrafish 2010;7:219-231.

23. Lawrence C. The husbandry of zebrafish (Danio rerio): a review. Aquaculture 2007;269:1-20.

24. Kolkovski S. Microdiets as alternatives to live feeds for fish larvae in aquaculture: improving the efficiency of feed particle utilization. In: Advances in Aquaculture Hatchery Technology. Allan G and Burnell G (eds), pp. 203-222, Woodhead Publishing, 2013.

25. Martins G, Diogo P, Pinto W, Gavaia PJ. Early transition to microdiets improves growth, reproductive performance and reduces skeletal anomalies in zebrafish (Danio rerio). Zebrafish 2019;16:300-307.

26. Martins G, Diogo P, Santos T, Cabrita E, Pinto W, Dias J, et al. Microdiet formulation with phospholipid modulate zebrafish skeletal development and reproduction. Zebrafish 2020;17:27-37.

27. Spence R, Gerlach G, Lawrence C, Smith C. The behavior and ecology of the zebrafish, Danio rerio. Biol Rev Camb Philos Soc 2008;83:13-34.

28. Kungvankij P, Tiro LB Jr., Pudadera BJ Jr., Potestas IO. Biology and Culture of Sea Bass (Lates calcarifer). NACA Training Manual Series No. 3, Reprinted June 1989 as Aquaculture Extension Manual No. 11, SEAFDEC AQD, Philippines.

29. Parazo MM, Garcia LMaB, Ayson EG, Fermin AC, Almendras JME, Reyes DM, et al. Sea Bass Hatchery Operations. Aquaculture Extension Manual No. 18, SEAFDEC AQD, Philippines, 1990.

30. Moretti A, Pedini Fernandez-Criado M, Cittolin G, Guidastri R. 1999. Manual on Hatchery Production of Seabass and Gilthead Seabream. Volume 1. p. 194, FAO, Rome.

31. Reitan KI, Rainuzzo JR, Øie G, Olsen, Y. A review of the nutritional effects of algae in marine fish larvae. Aquaculture 1997;155:207-221.

32. Støttrup JG, McEvoy LA. Live Feeds in Marine Aquaculture. p. 318, Blackwell Science Ltd, 2003.

33. Skjermo J, Vadstein O. The effect of microalgae on skin and gut microbial flora of halibut larvae. In: Proceedings 
from International Conference on Fish Farming Technology. Reinerstsen H, Dalhe LA, Jorgensen L, and Tvinnerein K (eds). pp. 61-67, Trondheim, August 1993.

34. Lavens P, Sorgeloos P. Manual on the production and use of live food for aquaculture. FAO Fisheries Technical Paper. No. 361. p. 295, FAO, Rome, 1996.

35. Atashbar B, Agh N, Beladjal L, Jalili R, Mertens J. Effects of temperature on survival, growth, reproductive and life span characteristics of Branchinecta orientalis G. O. Sars, 1901 (Branchipoda, Anostraca) from Iran. Crustaceana 2012;85:1099-1114.

36. Pormehr N, Beladjal L, Agh N, Atashbar B, Van Stappen G. Mass culture of fairy shrimp Branchinecta orientalis (G. O. Sars 1901) (Crustacea: Anostraca) using effluent of rainbow trout Oncorhynchus mykiss (Walbaum 1792) ponds. Aquac Res 2017;48:5455-5462.

37. Pormehr N, Agh N, Beladjal L, Atashbar B, Van Stappen G. Reproductive performance of fairy shrimp Branchinecta orientalis (G. O. Sars 1901) (Crustacea: Anostraca), fed with effluent of rainbow trout Oncorhynchus mykiss (Walbaum 1792) ponds. Aquac Nutr 2018;24:1502-1508.

38. Wood AW, Duan C, Bern HA. Insulin-like growth factor signaling in fish. Int Rev Cytol 2005;243:215-285.

39. Soliman AT, Hassan AEI, Aref MK, Hintz RL, Rosenfeld RG, Rogol AD. Serum insulin-like growth factor I and II concentrations and growth hormone and insulin responses to arginine infusion in children with protein-energy malnutrition before and after nutritional rehabilitation. Pediatr Res 1986;20:1122-1130.

40. Straus DS, Takemoto CD. Amino acid limitation negatively regulates insulin-like growth factor II mRNA levels and E-domain peptide secretion at a post-transcriptional step in BRL-3A rat liver cells. J Biol Chem 1988;263:18404-18410.

41. Chauvigné F, Gabillard JC, Weil C, Rescan PY. EVect of refeeding on IGFI, IGFII, IGF receptors, FGF2, FGF6, and myostatin mRNA expression in rainbow trout myotomal muscle. Gen Comp Endocrinol 2003;132:209-215.

42. Thissen J-P, Beauloye V, Ketelslegers J-M, Underwood LE. Regulation of insulin-like growth factor-I by nutrition. In: IGF and Nutrition in Health and Disease. Houston MS, Holly JMP, and Feldman EL (eds), pp. 25-52, Humana Press Inc., Totowa, NJ, 2004.

43. Villamizar N, Vera LM, Foulkes NS, Sánchez-Vázquez FJ. Effect of lighting conditions on zebrafish growth and development. Zebrafish 2014;11:173-181.

44. Haigh JJ. Role of VEGF in organogenesis. Organogenesis 2008;4:247-56.

45. Ullah MF, Ahmad A. Nutraceuticals and Natural Product Derivatives: Disease Prevention \& Drug Discovery. John Wiley \& Sons, Inc., 2019.

46. Samaee S-M, Manteghi N, Estévez A. Zebrafish as a model to screen the potential of fatty acids in reproduction. Zebrafish 2019;16:47-64.

47. Samaee S-M, Patzner RA, Mansour N. Morphological differentiation within the population of Capoeta capoeta gracilis (Cyprinidae, Teleostei) in one river of the south basin of Caspian Sea: a pilot study. J Appl Ichthyol 2009; 25:583-590.

48. Bradford MM. A rapid and sensitive method for the quantitation of microgram quantities of protein utilizing the principle of protein-dye binding. Anal Biochem 1976;72: 248-254.

49. Worthington CC. Worthigton Enzyme Manual Related Biochemical. 3rd edition. Freehold, NJ, 1991.
50. Iijima N, Tanaka S, Ota Y. Purification and characterization of bile salt activated lipase from the hepatopancreas of red sea bream, Pagrus major. Fish Physiol Biochem 1998;18: 59-69.

51. Garcia-Carreño FL, Haard NF. Characterization of proteinase classes in langostilla (Pleuroncodes planipes) and crayfish (Pacifastacus astacus) extracts. J Food Biochem 1993; 17:97-113.

52. Zhao D, Qin C, Fan X, Li Y, Gu B. Inhibitory effects of quercetinon angiogenesis in larval zebrafish and human umbilical vein endothelial cells. Eur J Pharmacol 2014;723: 360-367.

53. Livak KJ, Schmittgen TD. Analysis of relative gene expression data using real time quantitative PCR and the $2^{-\Delta \Delta C T}$ method. Method 2001;25:402-408.

54. Wilson C. Aspects of larval rearing. ILAR J 2012;53:169-178.

55. Barton B. Stress in fishes: a diversity of responses with particular reference to changes in circulating corticosteroids. Integ Comp Biol 2002;42:517-525.

56. Paterson G, Ataria JM, Hoque ME, Burns DC, Metcalfe $\mathrm{CD}$. The toxicity of titanium dioxide nanopowder to early life stages of the Japanese medaka (Oryzias latipes). Chemosphere 2011;82:1002-1009.

57. Samaee S-M, Rabbani S, Jovanović B, Mohajeri-Tehrani MR, Haghpanah V. Evaluation of the efficacy of the hatching rate derived variables to assess toxicity of the nano-sized $\mathrm{TiO}_{2}$ particles in zebrafish (Danio rerio). Ecotox Environ Safe 2015;116:121-128.

58. Samaee S-M, Manteghi N, Yokel RA, Mohajeri-Tehrani MR. Morphometric characteristics and time to hatch as efficacious indicators for potential nanotoxicity assay in zebrafish. Environ Toxicol Chem 2018;37:3063-3076.

59. Leung TS, Bulkley RV. Effects of petroleum hydrocarbons on length of incubation and hatching success in Japanese medaka. Bull Environ Contam Toxicol 1979; 23:236-243.

60. Winnicki A, Radziun MS, Radziun K. Structural and mechanical changes in the egg membranes of Salmo gairdneri Rich. during the period of hatching of the larvae. Acta Ichthyol Piscat 1970;1:7-18.

61. Yamamoto M. Hatching gland and hatching enzyme. In: Medaka (Killifish): Biology and Strains. Yamamoto T (ed), pp. 73-79, Keigaku Pub Co, Tokyo, 1975.

62. Kashiwada S. Distribution of nanoparticles in the seethrough medaka (Oryzias latipes). Environ Health Persp 2006;114:1697-1702.

63. Oberdörster E, Zhu S, Blickley TM, McClellan-Green P, Haasch ML. Ecotoxicology of carbon-based engineered nanoparticles: effects of fullerene (C60) on aquatic organisms. Carbon 2006;44:1112-11120.

64. Cheng J, Flahaut E, Cheng SH. Effect of carbon nanotubes on developing zebrafish (Danio rerio) embryos. Environ Toxicol Chem 2007;26:708-716.

65. Liu Han, Guo X, Gooneratne R, Lai R, Zeng C, Zhan F, et al. The gut microbiome and degradation enzyme activity of wild freshwater fishes influenced by their trophic levels. Sci Rep 2016;6:24340.

66. Yokoe Y, Yasumasu I. The distribution of cellulase in invertebrates. Comp Biochem Phys 1964;13:323-338.

67. Noori F, Van Stappen G, Sorgeloos P. Preliminary study on the activity of protease enzymes in Persian sturgeon (Acipenser persicus Borodin, 1897) larvae in response to different diets: effects on growth and survival. Aquac Res 2012;43:198-207. 
68. Kawai S, Ikeda S. Studies on digestive enzymes of fishesII. Effect of dietary change on the activities of digestive enzymes in carp intestine. Bull Japan Soc Sci Fish 1972;38: 265-270.

69. Sargent JR, Tocher DR, Bell JG. The lipids. In: Fish Nutrition. Halver JE and Hardy RW (eds). pp. 181-257, Academic Press, Elsevier, San Diego, CA, 2002.

70. Mourente G, Dick JR, Bell JG, Tocher DR. Effect of partial substitution of dietary fish oil by vegetable oils on desaturation and b-oxidation of [1-14C]18:3n-3 (LNA) and [1-14C]20:5n-3 (EPA) in hepatocytes and enterocytes of European sea bass (Dicentratchus labrax L.). Aquaculture 2005;248:173-186.

71. Tocher DR, Dick JR, MacGlaughlin P, Bell JG. Effect of diets enriched in D6 desaturated fatty acids (18:3n-6 and $18: 4 n-3)$, on growth, fatty acid composition and highly unsaturated fatty acid synthesis in two populations of Arctic charr (Salvelinus alpinus L.). Comp Biochem Physiol B 2006;144:245-253.

72. Takahashi H. Juvenile hermaphroditism in the zebrafish, Brachydanio rerio. Bull Fac Fish Hokkaido Univ 1977;18: 57-65.

73. Brannen KC, Panzica-Kelly JM, Danberry TL, AugustineRauch KA. Development of a zebrafish embryo teratogenicity assay and quantitative prediction model. Birth Defects Res B Dev Reprod Toxicol 2010;89:66-77.

74. George S, Xia T, Rallo R, Zhao Y, Ji Z, Lin S, et al. Use of a high-throughput screening approach coupled with in vivo zebrafish embryo screening to develop hazard ranking for engineered nanomaterials. ACS Nano 2011;5: 1805-1817.

75. Ahmadi N, Samaee SM, Yokel RA, Tehrani A. Imatinib mesylate effects on zebrafish reproductive success: gonadal development, gamete quality, fertility, embryo-larvae viability and development, and related genes. Toxicol Appl Pharmacol 2019;379:114645.

76. Wirbisky SE, Weber GJ, Sepúlveda MS, Lin T-L, Jannasch AS, Freeman JL. An embryonic atrazine exposure results in reproductive dysfunction in adult zebrafish and morphological alterations in their offspring. Sci Rep 2016;6:21337.

77. Glencross BD. Exploring the nutritional demand for essential fatty acids by aquaculture species. Rev Aquacult 2009;1:71-124.

78. Makkar HPS, Tran G, Heuzé V, Ankers P. State-of-the-art on use of insects as animal feed. Anim Feed Sci Technol 2014;197:1-33.

79. Chow KW. Microencapsulated egg diets for fish larvae. In: "Fish Feed Technology" Food and Agriculture Organization of the United Nations. 1980. Available at http://www .fao.org/3/x5738e00.htm\#Contents

80. Merchie G. Use of nauplii and meta-nauplii. In: Manual on the Production and Use of Live Food for Aquaculture. Lavens P and Sorgeloos P (eds), Food and Agriculture Organization of the United Nations, FAO Fisheries Technical Paper 361, Rome, 1996.
81. Bahary N, Goishi K, Stuckenholz C, Weber G, Leblanc J, Schafer CA, et al. Duplicate VegfA genes and orthologues of the KDR receptor tyrosine kinase family mediate vascular development in the zebrafish. Blood 2007;110:36273636.

82. Chakraborty C, Hsu CH, Wen ZH, Lin CS, Agoramoorthy G. Effect of caffeine, norfloxacin and nimesulide on heartbeat and VEGF expression of zebrafish larvae. J Environ Biol 2011;32:179-183.

83. Cao Y. Positive and negative modulation of angiogenesis by VEGFR1 ligands. Sci Signal 2009;2:re1.

84. Breier G, Albrecht U, Sterrer S, Risau W. Expression of vascular endothelial growth factor during embryonic angiogenesis and endothelial cell differentiation. Development 1992;114:521-532.

85. Ferrara N. Molecular and biological properties of vascular endothelial growth factor. J Mol Med (Berl) 1999;77:527543.

86. Duan C. Nutritional and developmental regulation of insulin-like growth factors in fish. J Nutr 1998;128(2 Suppl): 306S-314S.

87. White YAR, Kyle JT, Wood AW. Targeted gene knockdown in zebrafish reveals distinct intraembryonic functions for insulin-like growth factor II signaling. Endocrinology 2009; 150:4366-4375.

88. Zou S, Kamei H, Modi Z, Duan C. Zebrafish IGF genes: gene duplication, conservation and divergence, and novel roles in midline and notochord development. PLoS One 2009;4:e7026.

89. Chauvigné F, Gabillard JC, Weil C, Rescan PY. Effect of refeeding on IGFI, IGFII, IGF receptors, FGF2, FGF6, and myostatin mRNA expression in rainbow trout myotomal muscle. Gen Comp Endocrinol 2003;132:209-215.

90. Kimmel CB, Ballard WW, Kimmel SR, Ullmann B, Schilling TF. Stages of embryonic development of the zebrafish. Dev Dyn 1995;203:253-310.

91. Eivers E, McCarthy K, Glynn C, Nolan CM, Byrnes L. Insulin-like growth factor (IGF) signalling is required for early dorso-anterior development of the zebrafish embryo. Int J Dev Biol 2004;48:1131-1140.

92. Zarantoniello M, Randazzo B, Truzzi C, Giorgini E, Marcellucci C, Vargas-Abúndez JA, et al. A six-months study on Black Soldier Fly (Hermetia illucens) based diets in zebrafish. Sci Rep 2019;9:8598.

$$
\begin{array}{r}
\text { Address correspondence to: } \\
\text { Seyed-Mohammadreza Samaee, PhD } \\
\text { Aquatic Lab } \\
\text { Faculty of Veterinary Medicine } \\
\text { Urmia University } \\
\text { Urmia } 165 \\
\text { Iran }
\end{array}
$$

E-mail: seyedmohammadreza.samaee@gmail.com 